\title{
Heterogeneity of UK Residential Heat Demand and its Impact on the Value Case for Heat Pumps
}

\author{
Jack Flower*, Graeme Hawker, Keith Bell \\ Institute for Energy and Environment, Department of Electronic and Electrical Engineering, University of \\ Strathclyde, UK
}

\begin{abstract}
This study examines the heterogeneity of UK residential heat demand and how this diversity, along with social demographic and dwelling characteristic diversity, impacts the value case for heat pumps (HPs). The marginal abatement cost (MAC) of HPs is highly sensitive to the level of heat demand and technology assumptions. Care must be taken when interpreting the results from models with a high degree of aggregation. For similar dwellings, heat demand typically becomes lower for demographic groups that have higher levels of deprivation. For similar dwellings and demographics, households using natural gas typically have double the enduse heat demands of households with electric storage heaters. Therefore, if access to heating with similar costs to that of natural gas-fired heating is gained, the direct rebound effect suggests that the heat demands of households heated with electric storage heaters could double, particularly for households that have relatively high proportions of energy expenditure. Heating technology and building efficiency support mechanisms need to simultaneously address the wider goal of decarbonisation while reducing fuel poverty, and to incorporate measures of demand diversity into future assessment of heat policy that recognises how this rebound may oppose decarbonisation efforts but enable improvements in comfort, welfare and health standards.
\end{abstract}

Keywords:

Fuel Poverty; Rebound Effect; Marginal Abatement Cost; Demand Diversity; Deep Decarbonisation

\section{Introduction}

The Committee for Climate Change (CCC), an independent, statutory body established under the UK Climate Change Act (HM Government, 2008), has, in its review of UK progress towards meeting 2030 and 2050 carbon targets (CCC, 2019a), continued to highlight the ongoing difficulties and lack of progress in decarbonising the heat sector.

Decarbonising UK residential heating in line with a net-zero greenhouse gas (GHG) emissions target, which the UK Government has recently legislated (HM Government, 2019), is a major challenge that requires a considerable shift away from unabated natural gas use by 2050 , which at present is used by around $85 \%$ of households for heating purposes (BEIS, 2018a). It is outlined that, the share of low carbon heating will need to increase from $4.5 \%$ in 2017 to $90 \%$ in $2050^{1}$, and unlike the previous $80 \%$ target where there is flexibility not to pursue some emissions reductions options - a net-zero target requires aggressive decarbonisation options even where faced with significant cost and technical hurdles (CCC, 2019b).

The electrification of heat demand through heat pumps ${ }^{2}$ (HPs) is likely to play a key role in delivering deep emissions reductions for residential heating in the UK (Broad et al., 2020), whether standalone or as an element in a hybrid system (CCC, 2019b). Hybrid HP systems could decarbonise existing homes on the gas grid while keeping open the option of switching the remaining gas supply to hydrogen at a later date (CCC, 2018). However, the suitability and cost-effectiveness of HPs will vary across the housing stock. Therefore, there is a requirement for policymakers to understand the cost-effectiveness and impact of implementing low carbon heating options taking into account the heterogeneity of the housing stock, as a transition to a netzero future will require action across all dwelling types and social demographics, including households that are in fuel poverty ${ }^{3}$.

The cost-effectiveness of HPs relative to reference heating options for emissions reductions can be found by determining the amount of additional money that must be spent over the lifetime of the heat pump to obtain a certain level of emissions reductions. This is known as the Marginal Abatement Cost (MAC) and is usually described as $£$ per tonne of emissions reduction. The lower the MAC the more cost-effective an abatement option is relative to a reference option. A negative MAC value means that (over the lifetime of the abatement option) there is potential to save money at the same time as reducing emissions. Deriving MAC values is not limited to analysis of GHG emissions. For example, following the oil price crises of the 1970 s, MAC values were first used to assess the cost of measures to reduce electricity consumption $[\$ / \mathrm{kWh}]$ (Meier et al., 1982).

\footnotetext{
${ }^{1} 2017$ represents share of heat from low-carbon sources, 2050 represents the number of existing homes with low-carbon heat (CCC, 2019b)

2 The term heat pump (HP) is used throughout this paper to generalise HP systems. HP systems can be distinguished by the method used to source energy and the distribution method for heating/cooling. This study is only concerned with a water-based heat distribution method. Therefore, HPs are only sub-categorised here as air-source heat pump (ASHP) and ground-source heat pump (GSHP) systems, which are used in instances when HP systems need to be differentiated from each other.

${ }^{3}$ Fuel poverty, defined by (HM Government, 2000) as: "a household living on a lower income in a home which cannot be kept warm at reasonable cost", is also a key driver of UK heat policy (BEIS, 2018c, 2017b, 2017c). In England, the Low Income High Cost (LIHC) indicator is used to classify a household as fuel poor if their required energy expenditure (ENEX) exceeds the national median and their income, after the deduction of required ENEX, lies below the income poverty threshold - currently $60 \%$ of median income.
}

${ }^{*}$ Corresponding author at: University of Strathclyde, Institute for Energy and Environment, Technology \& Innovation Centre, 99 George Street, Glasgow, G1 1RD, UK. E-mail address: jack.flower@strath.ac.uk (Jack Flower). 
Deriving MAC values is an important method in allowing policymakers to prioritise different abatement measures to determine what the most cost-effective options are likely to be, and where public money may be spent most efficiently. The UK Government aspires to upgrade the energy performance of 17 million homes so that a minimum energy performance certificate (EPC) rating of $\mathrm{C}$ - on a scale of $\mathrm{A}$ (best) to $\mathrm{G}$ (worst) is realised where "practical", "cost-effective" and "affordable" (BEIS, 2017a). For this, they define that abatement measures for households are "cost-effective" when below a threshold identified as lying between $£ 100-£ 200 /$ tCO2e (UK Parliament, 2019).

The derivation, application and usefulness of MAC values has been systematically reviewed in (Huang et al., 2016; Kesicki and Strachan, 2011; Sathaye and Shukla, 2013). The methods used to derive MAC values can generally be divided between 'expert-based' approaches and 'systems-based' approaches. An expert-based (or 'off-model') approach involves individual assessment of abatement measures, such that, the cost and emission reduction potential of each measure is assessed in isolation, see for example (CBI Climate Change Task Force, 2007; McKinsey \& Company, 2009). The systems-based approach involves the use of modelling where the corresponding $\mathrm{CO} 2$ emissions reduction is recorded along with the associated costs. According to the model employed, this can be further differentiated into those based on bottom-up models, such as energy systems models, and top-down models, such as computable general equilibrium (CGE) models. There are no shortages of models used for assessing carbon mitigation, see (Hall and Buckley, 2016; Sathaye and Shukla, 2013).

National scale whole energy systems models, such as UK TIMES (UKTM) ${ }^{4}$ (notably used by the UK Government to inform the 2017 Clean Growth Strategy (BEIS, 2017b)), are generally configured to be spatially and temporally aggregated and to represent sectors with low granular detail. While this reduces the volume of data to be managed and the number of constraints to be defined by modellers, and is therefore an efficient method for energy systems modelling studies that are not concerned with one particular sector, it can overlook diversity within sectors and key outliers in the system may be absent. Therefore, national models configured like this are likely to be too aggregate to support tailored and targeted policy interventions, particularly for those needed to support a retrofit strategy in the residential sector.

The author in (Dodds, 2014) discusses how disaggregation offers the advantage of showing optimal technologies for different dwelling types, and enables the impact of broad policies to be explored across the housing stock to better inform sector-specific policies. It is suggested that the results from energy systems modelling can be used as boundary conditions in a housing stock model to obtain significant disaggregation. Within least-cost optimisation models, assumptions are also made about the future costs and technical performance of technologies, and this reduction may disguise the relative competitiveness of different technologies at distinct levels of maturity, with minimal consideration of 'regret' (Hawker and Bell, 2019).

This study explores the heterogeneity of UK residential heat demand and assesses how this diversity, along with dwelling characteristic and social demographic diversity, impacts the value case for standalone and hybrid HP systems. For this, the MAC of implementing HPs relative to reference heating options is found using an 'off-model' approach for the range of UK end-use household heat demands.
As stressed in (Kesicki and Strachan, 2011), the off-model approach by nature does not account for system wide distortions and interactions in energy systems and the wider economy, that would perhaps be considered by a systems-based approach using sectoral or economy-wide modelling. Further, MAC values alone are often narrow in their scope of what is utility, where indirect benefits such as welfare, comfort and health have to be assessed separately. However, the off-model approach used here for deriving MAC values offers the benefit of comparing the relative competitiveness of technologies as well as being an efficient method of obtaining significant sectoral disaggregation. This is important as the costeffectiveness of abatement measures is partly determined by the level of end-use demand - and thus energy consumed - over the lifetime of the mitigating measure. Moreover, heat demand itself is considerably diverse throughout the UK, and is influenced by a number of factors - not just dwelling characteristics and type of heating systems, but also more complex factors such as occupant prosperity, comfort requirements and lifestyle. This study therefore aims to highlight the importance of capturing within-sector heterogeneity so policy can correctly reflect the nuances and outliers of UK residential heating, as will be required to meet an ambitious net-zero target. Furthermore, this study also aims to provide further weight for the argument of using a suite of tools and methods when assessing the merit of decarbonisation efforts, as concluded in (Kesicki and Strachan, 2011).

The remainder of this paper is organised as follows: Section 2 derives end-use heat demands and examines the influence that dwelling characteristics, and socio-economic and demographic factors have on heat demand; Section 3 describes the methods and assumptions used to derive the MAC values: Section 4 presents the MAC results which includes a sensitivity analysis into technology assumptions for heat pump systems; and finally, Section 5 draws conclusions and policy implications around the key findings.

\section{Heterogeneity of UK Residential Heat Demand}

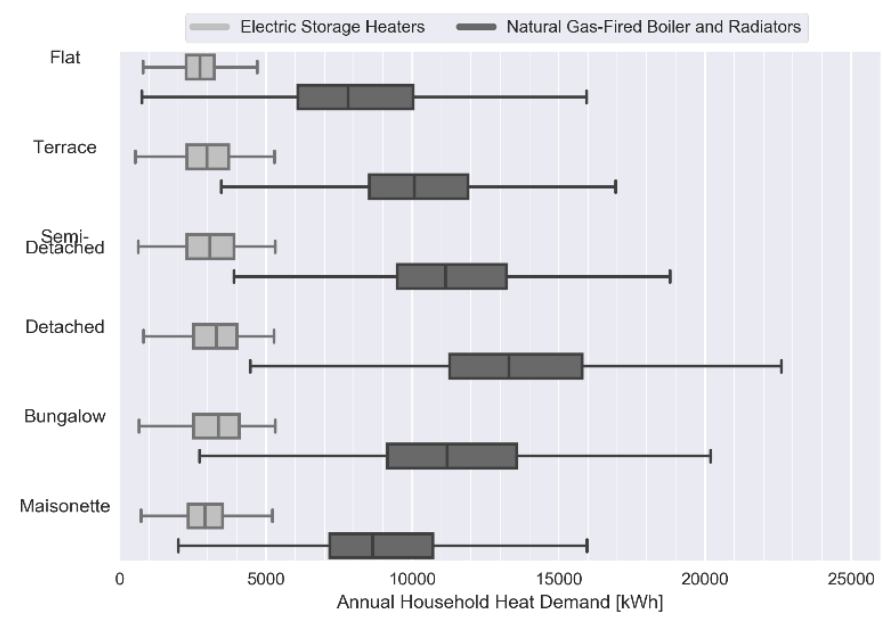

Figure 1 Distribution of UK annual household heat demands by dwelling and main heating type. Demands are derived based on gas and electricity meter consumption data averaged over the years 2016 and 2017.

Disaggregated annual household end-use heat demand for the UK is estimated from actual metered energy consumption data, sourced from sub-national electricity (BEIS, 2019a) and gas (BEIS, 2019b) consumption meter data, by making assumptions about other household uses of energy and the conversion efficiency of heating systems. A full description of the methods and assumptions is provided in Appendix A.

${ }^{4}$ UKTM (or UK TIMES) is a bottom-up single region whole energy systems model of the UK developed using the IEA-ETSAPs TIMES (The Integrated

MARKAL-EFOM System) modelling framework (Loulou and Labriet, 2008). 

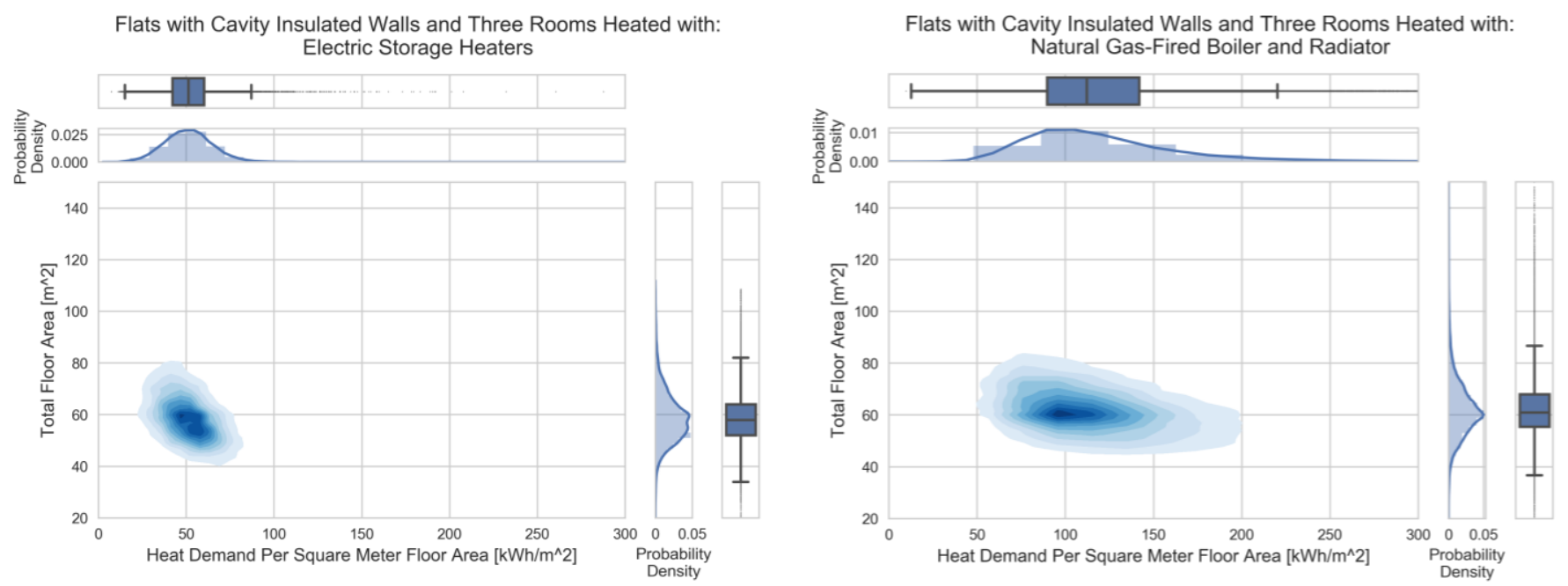

Figure 2 Annual household heat demand normalised as the heat demand per square meter floor area for the year 2016 against total floor area for flats with cavity insulated walls and three heated rooms. The left graph shows the results for 63,863 flats with electric storage heaters and the right graph is for 190,068 flats with a natural gas-fired boiler and radiators. On average, the normalised heat demands for households with a natural gas-fired boiler and radiators is more than double compared to that of households heated with electric storage heaters.

Figure 1 depicts the distribution of annual household heat demand estimates by dwelling type for households heated with electric storage heaters, compared with households heated by a natural gas-fired boiler and radiators (which are the most prominent types of heating systems that use either electricity directly ${ }^{5}$ or natural gas respectively (Ministry of Housing Communities \& Local Government, 2018)). The annual household heat demand estimates for households that are heated with electrical storage heaters are significantly lower, for all dwelling types, than the demands for households heated with a natural gas-fired boiler and radiators.

\subsection{Normalising heat demand and accounting for socio- economic and demographic factors}

In the UK, dwellings heated with electric storage heaters are typically smaller than dwellings heated with a natural gas-fired boiler and radiators (see Appendix B). However, by normalising the heat demand estimates as the thermal energy per square meter floor area delivered by heating systems over a year, and applying filters to obtain dwellings with similar characteristics, it is found that the normalised heat demands for households heated with a natural gas-fired boiler and radiators are, on average, more than double compared to that of households with electric storage heaters - see Table 1 showing results for flats, the most prominent dwelling type for households heated with electric storage heaters (see Appendix B). Figure 2 depicts the distribution of normalised heat demand against total floor area for flats with insulated cavity walls and three heated rooms. Note, similar distributional patterns are observed for all dwelling cases in Table 1, but for brevity only the distributions for one example case are depicted. See Appendix A.2 for more information and additional analysis that validates the normalisation and filtering approach used here to produce these findings.

The impact of socio-economic and demographic factors on heat demand is considered here to understand why, for similar dwelling characteristics, the heat demands for households with natural gas-fired heating are on average more than double than for those heated by electric storage heaters. For this, the following information for each household is used; index of multiple deprivation (IMD) ${ }^{6}, 2011$ OAC index values for residential-based area classifications ${ }^{7}$ and unemployment data ${ }^{8}$.

Table 1

Differences for average normalised annual heat demands for the year 2016 between flats heated with electric storage heaters and flats heated with a natural gas-fired boiler and radiators.

\begin{tabular}{llllll} 
& & \multicolumn{2}{l}{$\begin{array}{l}\text { Households Heated with Electric } \\
\text { Storage Heaters }\end{array}$} & $\begin{array}{l}\text { Households Heated with Natural } \\
\text { Gas-Fired Boiler and Radiators }\end{array}$ \\
\cline { 5 - 6 } $\begin{array}{l}\text { Number } \\
\text { of } \\
\text { Heated } \\
\text { Rooms }\end{array}$ & $\begin{array}{l}\text { Average Heat Demand Per } \\
\text { Meter Square Floor Area } \\
{\left[\mathrm{kWh} / \mathrm{m}^{\wedge} 2\right]}\end{array}$ & $\begin{array}{l}\text { Data } \\
\text { Sample } \\
\text { Size }\end{array}$ & $\begin{array}{l}\text { Average Heat Demand Per } \\
\text { Meter Square Floor Area } \\
{\left[\mathrm{kWh} / \mathrm{m}^{\wedge} 2\right]}\end{array}$ & $\begin{array}{l}\text { Data } \\
\text { Sample } \\
\text { Size }\end{array}$ \\
\hline $\begin{array}{l}\text { Flats with Cavity } \\
\text { Insulated Walls }\end{array}$ & 69.27 & 12,053 & 224.40 & 8,676 \\
& 2 & 59.28 & 78,838 & 154.79 & 147,320 \\
& 3 & 51.23 & 63,863 & 125.77 & 190,068 \\
& 4 & 45.60 & 4,866 & 117.69 & 35,494 \\
Flats with Solid & 1 & 77.39 & 3,157 & 353.52 & 6,802 \\
$\begin{array}{l}\text { Un-insulated } \\
\text { Walls }\end{array}$ & 2 & 60.42 & 11,256 & 223.13 & 66,717 \\
& 3 & 48.67 & 5,229 & 173.96 & 76,332 \\
& 4 & 43.71 & 762 & 147.50 & 23,418 \\
\hline
\end{tabular}

Variable significance testing using the Pearson and Spearman tests is carried out to distinguish the relationship between normalised heat demand and the assigned socio-economic and demographic values. The findings (presented in detail in the correlation matrices in Appendix C), indicate that for households with similar dwelling and heating system

\footnotetext{
${ }^{5}$ Electrical heating options using electricity directly are generalised for the purpose of this paper to mean that heat is generated using an electrical resistive element and does not include using heat transfer thermodynamic cycles, such as that used by heat pumps.

${ }^{6}$ The index of multiple deprivation (IMD) 2015 is the official measure of relative deprivation for small areas (or neighborhoods) in England. The IMD ranks every small area in England from 1 (most deprived area) to 32,844 (least deprived area) (Department for Communities and Local Government, 2015).

${ }^{7}$ The residential-based area classifications were designed by the authors in (Gale et al., 2016) in collaboration with the Office for National Statistics using k-means clustering based on 60 standardised variables from the 2011 UK Census, such as age band, status and type of employment, method of travel to work, and type of housing. An example sub-group is ' $7 b 2$ Deprived Neighbourhoods' which is characterised as having high rates of unemployment, and a high number of residents living in social housing that are also flats. Residential-based area classifications have been used in past studies for a local-area resource-access model (LARA) to demonstrate how spatially-variant social demographics contribute different amounts to commodity flows of physical material goods in (Druckman et al., 2008) and household energy consumption in (Druckman and Jackson, 2008).

${ }^{8}$ Recognising that prosperity is temporally dynamic as well as spatially dynamic - i.e. financial challenges can enter or leave an area over short or long periods of time - unemployment rate data in the form of rates of economically active population claiming Job Seekers Allowance (JSA) (the main unemployment benefit in the UK) were sourced from (Office for National Statistics, 2018) for this study. The time period for unemployment data was selected to correspond to the time period of electricity and gas meter consumption data used to derive the heat demand estimates.
} 
FLAT, Cavity Insulated Walls, 2 Room(s) Heated with: Electric Storage Heaters

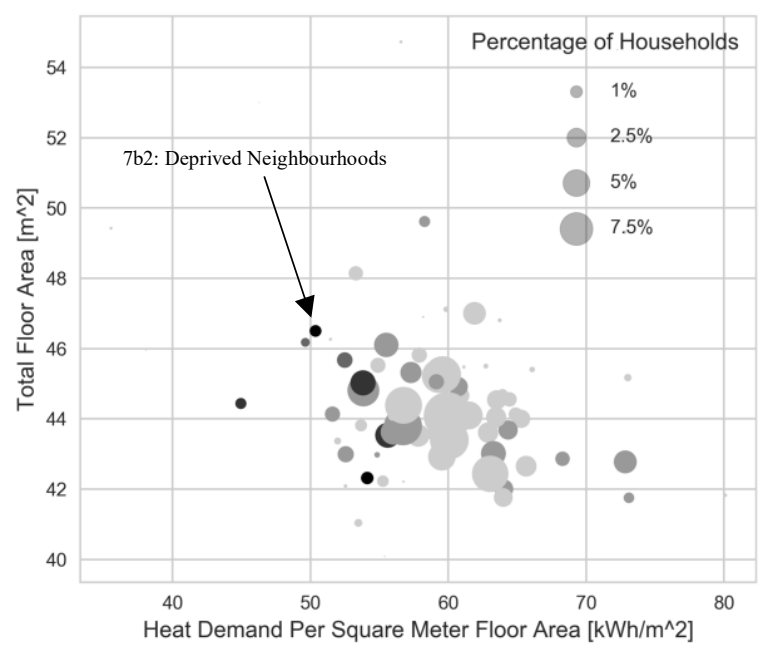

FLAT, Cavity Insulated Walls, 2 Room(s) Heated with: Natural Gas-Fired Boiler and Radiators

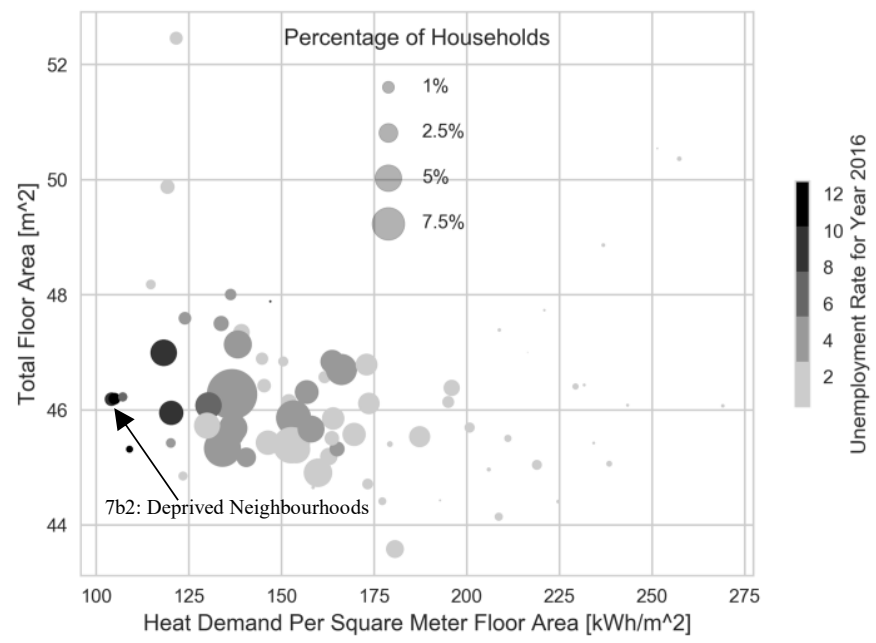

Figure 3. Graphical results showing average heat demand, normalised by floor area, for each residential-based area subgroup for cavity walled flats with two heated rooms. The left graph is for households with electrical storage heaters and the right graph is for households with natural gas-fired boilers and radiators. The colour gradient indicates the rate of economically active population claiming Job Seekers Allowance (JSA). Note the graphs have different axis values so that the diversity for each heating type can be more clearly depicted.

characteristics, normalised heat demand typically has a moderate-to-strong positive correlation with variables such as owner occupied households, households with two or more cars, households with no/non-dependent children, and less deprived areas as indicated by higher IMD values. Heat demand typically has a moderate-to-strong negative correlation with variables such as unemployment, social renting, overcrowding, households not using private transport to commute to work and more deprived areas as indicated by lower IMD values. However, the strength of these relationships varies for different dwelling characteristics.

Social demographic and economic diversity impacts heat demand, as illustrated by Figure 3 that depicts the diversity of average heat demands for each of the different residential-based area classifications. However, for households with similar dwelling characteristics, the level of deprivation is largely similar for both heating types (see Appendix D). That is, dwellings with similar characteristics heated with electric storage heaters do not have a higher proportion of households that are deprived compared to similar dwellings heated with a natural gas-fired boiler and radiators. See Figure 3 that indicates the presence of households within the cluster " $7 \mathrm{b2}$ Deprived Neighbourhoods' for both of the heating types. This indicates that the difference in normalised heat demands between the heating types for households with similar dwelling characteristics must largely be due to the higher unit cost of thermal energy delivered by electrical resistive heating compared to natural gas-fired heating.

This finding is in line with a study conducted in (Ofgem, 2015) that investigated the customer experience and engagement of households with electric heating by drawing on existing surveys and analysis. It was found that only a small proportion of households with electric storage heaters felt content with their ability to keep their homes warm compared to households using natural gas-fired heating. The explanation given is the inability to heat to a comfortable temperature, as well as high costs and self-rationing that is typically accentuated for households with old electric storage heaters. Many of these households make use of supplementary heating, such as plug-in electrical resistive heaters (that have no storage capability), and, some households find a standard tariff better suited to their heating requirements and lifestyle than a time-ofuse tariff.
There is, therefore, realistic potential for the heat demands of households with electric storage heaters to increase, as per the direct rebound effect (Belaïd et al., 2018; Clinch and Healy, 2003; $\mathrm{Su}, 2019$ ), if access to a heating option with similar costs to that of natural gas-fired heating is gained. This finding could mean that the uptake of low carbon heating systems, such as HPs, does not necessarily represent an opportunity for a decrease in energy consumption if there is a high to low price change for operating costs for certain cases in the housing stock. However, as strongly emphasised in (Belaïd et al., 2018; Clinch and Healy, 2003; Kelly et al., 2016), value extends beyond simply reducing emissions and energy consumption, as mitigating measures, such as HPs, can also improve comfort, welfare and health standards. This finding is supported again by the analysis in (Ofgem, 2015) that found reports of high levels of satisfaction when households switched their heating system from electric storage heaters to either HPs or natural gas-fired heating.

The weakness with the comparative approach used here is that it is not practically possible with the data available to enact full control over the study sample and account for all variables. For example, the vast array of variables related to the building fabric, socio-economics and demographics, as well as variables related to the exact heating regimes executed by occupants (i.e. internal temperature, number of heating hours and tariffs used). Further to this, households with electric storage heaters only account for around 5\% of the housing stock. Therefore, building on these findings, a comprehensive economic appraisal, in a similar vein to the work in (Belaïd et al., 2018), could provide detailed quantitative evidence on the magnitude of potential demand rebounds for low carbon heating uptake across the entire UK housing stock.

It is important for energy analysis to account for the rebound effect, among other more 'hidden factors' that are generally not picked up by engineering models (Gillingham and Palmery, 2014). The findings from this further work would be relevant for energy systems modellers that are concerned with incorporating consumer behaviour into energy models by using demand elasticities, as discussed in (Dodds, 2014). More specifically, the demand elasticities could be used to reflect an appropriate change in end-use demand for events that affect operating costs, such as from technology-specific subsidies or energy market interventions. This would therefore enable 


\begin{tabular}{|c|c|}
\hline \multicolumn{2}{|l|}{ Nomenclature } \\
\hline MAC & $\begin{array}{l}\text { Marginal Abatement Cost, or the cost-effectiveness of the mitigating measure to reduce carbon emissions } \\
\text { over the lifetime of the mitigating measure, in } £ 2015 \text { per tonne of } \mathrm{CO}_{2} \text { reduction }\end{array}$ \\
\hline TOTEX $X_{N P C, \text { Diff }}$ & $\begin{array}{l}\text { Net present value of the sum of the difference in total costs (capital, installation, operational and } \\
\text { maintenance) over the lifetime of the mitigating measure, } £ 2015\end{array}$ \\
\hline$E M M_{\text {Diff }}$ & Carbon emissions mitigated during the lifetime of the mitigating measure, $\mathrm{tCO}_{2}$ \\
\hline CAPEX $X_{\text {Diff }}$ & Difference in upfront capital and installation costs, $£ 2015$ \\
\hline$O P E X(t)_{D i f f}$ & Difference in operational and maintenance costs in year $t, £ 2015$ \\
\hline$D F(t)$ & Discount Factor for a given year $t$, based on the Discount Rate (DR) \\
\hline$M M$ & Subscript used to define Mitigating Measure \\
\hline $\operatorname{Ref}$ & Subscript used to define Reference Technology \\
\hline$M M x$ & $\begin{array}{l}\text { This subscript is used when a heating option for a mitigating measure consists of more than one } \\
\text { technology, such as in a hybrid heat pump system. The } x \text { is replaced with a letter allocated to signify the } \\
\text { heating technology in question (e.g. } a, b) \text {. }\end{array}$ \\
\hline CAPEX & Total upfront capital and installation costs of a heating system, $£ 2015$ \\
\hline$L$ & Approximate lifetime of technology (estimated as the technical design life), years \\
\hline$A H D$ & Annual Heat Demand of a household comprising of both end-use space and water heating demand, kWh. \\
\hline$R E T A I L(t)$ & Retail price for one unit of energy type used by the technology for the given year $t, £ 2015 / \mathrm{kWh}$ \\
\hline PF & $\begin{array}{l}\text { Technology performance factor, expressed as a co-efficient. For heat pump systems, this represents the } \\
\text { seasonal performance factor (SPF) for the typical annual climate of the UK. }\end{array}$ \\
\hline $\operatorname{EXTRA}(t)$ & Extra annual costs, such as annual service and maintenance costs for year $t, £ 2015$ \\
\hline$C I(t)$ & Carbon intensity per unit of energy consumed by the technology for a given year $t$, tonne $\mathrm{CO}_{2} / \mathrm{kWh}$ \\
\hline
\end{tabular}

$$
\begin{aligned}
& M A C=\frac{T O T E X_{N P C, D i f f}}{E M M_{D i f f}} \\
& T O T E X_{N P C, D i f f}=C A P E X_{D i f f}+\sum_{t=1}^{L_{M M}}\left[\operatorname{OPEX}(t)_{D i f f} \times D F(t)\right] \\
& C A P E X_{\text {Diff }}=C A P E X_{M M}-C A P E X_{R e f} \\
& \operatorname{OPEX}(t)_{D i f f}=A H D \times\left(\frac{R E T A I L(t)_{M M}}{P F_{M M}}-\frac{R E T A I L(t)_{R e f}}{P F_{R e f}}\right)+\operatorname{EXTRA}(t)_{M M}-\operatorname{EXTRA}(t)_{R e f} \\
& D F(t)=\frac{1}{(1+D R)^{t}} \\
& E M M_{\text {Diff }}=\sum_{t=1}^{L_{M M}}\left[A H D \times\left(\frac{C I(t)_{M M}}{P F_{M M}}-\frac{C I(t)_{R e f}}{P F_{R e f}}\right)\right]
\end{aligned}
$$

Note: Equations (7) and (8) replace equations (4) and (6) respectively when modelling a mitigating heating option that consists of more than one technology that has different characteristics (e.g. proportion of heat demand serviced, fuel type, performance factor, etc.) such as for hybrid heat pump systems.

$$
\begin{aligned}
& \operatorname{OPEX}(t)_{D i f f}=A H D a \times \frac{R E T A I L(t)_{M M a}}{P F_{M M a}}+A H D b \times \frac{R E T A I L(t)_{M M b}}{P F_{M M b}}-A H D \times \frac{R E T A I L(t)_{R e f}}{P F_{R e f}}+\operatorname{EXTRA}(t)_{M M a} \\
& +\operatorname{EXTRA}(t)_{M M b}-\operatorname{EXTRA}(t)_{R e f} \\
& E M M_{\text {Diff }}=\sum_{t=1}^{L_{M M}}\left[A H D a \times \frac{C I(t)_{M M a}}{P F_{M M a}}+A H D b \times \frac{C I(t)_{M M b}}{P F_{M M b}}-A H D \times \frac{C I(t)_{R e f}}{P F_{R e f}}\right]
\end{aligned}
$$

policy to better account for the realities of decarbonisation efforts.

\section{Methods, Data \& Assumptions for MAC Analysis}

The method used to derive the MAC values for this study over representative heat demands for the UK (as derived in Section 2 ) is denoted by equations (1) to (8). Equation (1) is the overall equation, with the MAC being the ratio between the net present cost of all the differences in upfront capital costs and operational and maintenance costs over the lifetime of the mitigating measure, divided by the amount of carbon emissions reductions over the same period, as compared to a reference technology. Equations (2) to (6) break down equation (1) into more detail. Equations (7) and (8) are used instead of equations 
(4) and (6) respectively when the mitigating heating option consists of two technologies that have separate characteristics, such as for a hybrid air-source heat pump (ASHP) system. This method is largely based on that defined in (Ibrahim and Kennedy, 2016).

\subsection{Assumptions and input data for MAC derivation}

The reference technologies considered in this study reflect the most commonly used heating options at present in the UK. Aside from the extensive use of natural gas-fired heating as previously discussed, the next most prominent heating options are electrical resistive heating and fuel oil-fired heating, which account for around $5.6 \%$ and $3.7 \%$ of total households respectively (BEIS, 2018a).

Natural gas-fired heating typically involves the use of a combination boiler that provides instantaneous hot water, and delivers space heating through a wet heat distribution system consisting of wall-mounted radiators. For an electrical resistive heating system, this typically involves the combination of electric storage heaters for space heating and an electric immersion water heater to provide hot water, often supported by a time-of-use tariff. GB tariffs such as Economy 7 or Economy 10 allow households to access lower cost electricity, typically at night time, compared to standard tariff electricity (Ofgem, 2015). Fuel oil-fired based systems work in a similar manner to natural gas-fired systems though using fuel oil stored in the household's own storage tank, refuelled via tanker deliveries. In GB, natural gas-fired heating is normally the lowest cost option (Which?, 2017). Households using other options are typically doing so either due to buildings not having gas distribution incorporated into their design (as with some tower blocks) or are located in off-gas grid areas, with high demand properties commonly utilising fuel oil due to the high unit cost of electrical resistive heating.

For heating systems, there is a trade-off between factors such as dwelling size and efficiency, heat demand, and the capacity, performance and cost of heating systems as well as the operational control strategy implemented by its users. For brevity, this study uses three representative examples for system sizing. These include modelling heating systems for a typical small, medium and large size UK dwelling. For these examples, it is assumed that households are already equipped with one of the reference heating systems, and considers either re-fitting the reference technology (with modern performance parameters) or retrofitting the household with a standalone or hybrid HP system. This evaluates policy mechanisms that intervene in the market at the point where a homeowner is looking to replace an ageing system that is perhaps costly to run and inefficient or even defective. See Table E.1 that details the baseline technology assumptions used in this study.

It is assumed that the typical small, medium and large size UK dwellings have three, five and eight rooms heated respectively. The representative examples are used to reflect the difference in capital costs as dwelling size changes. These costs differ due to the requirements for heating system capacity size, the number of heat emitters (or electric storage heaters for the electrical resistive heating case) requiring installation or retrofit, and the difference in installation costs such as for plumbing and wiring.

The majority of cost assumptions for heating systems sizing were obtained from (BEIS and Element Energy, 2017), and additional information has also been sourced from existing market surveys, field trials and expert opinion (Energy Saving Trust, 2018, 2013; Green Match, 2018; Which?, 2017).

A note must be made on the uncertainty for fixed operational and maintenance (O\&M) costs for HP systems observed in academic, industrial and governmental sources. For instance, fixed annual O\&M costs ranged from $£ 120$ to $£ 243$ for ASHP systems, see (BEIS and Element Energy, 2017; Jalil-Vega et al., 2020; Mitsubishi Electric, 2016; NIBE, 2020; Oluleye et al., 2018). The baseline O\&M costs modelled here are approximate median values found across the various sources. It happens to be the case that the O\&M costs for ASHP systems are the same as that for a natural gas-fired boiler. It is acknowledged that in reality O\&M costs for ASHP systems could be less than that for gas boiler systems. However, given the uncertainty in costs it is believed that the values modelled are reasonable for this study, but the reader should consider the points raised here when interpreting the MAC results.

Seasonal performance factor ${ }^{9}$ (SPF) of HPs depends on the thermal efficiency of the building supplied. This can reduce HP technology improvements if dwelling efficiency improvements are not conducted in parallel (Broad et al., 2020). This study focuses on retrofits, of which, would be carried out on a significant number of older dwellings in the UK where it may not be easy to obtain high SPFs at minimal scheme cost (i.e. accounting for dwelling efficiency measures). During a HP field trial (Energy Saving Trust, 2013) which monitored the performance of 44 HPs in the UK between 2010 and 2013, standalone ASHP installations operated with SPFs ranging from 2 to 3.6, with an average of 2.45. High levels of satisfaction were reported by the users of the trial $(80 \%$ satisfaction for space heating, and $84 \%$ satisfaction for hot water). Therefore, it is assumed that comfort levels of occupants were not compromised. For this study it is assumed that standalone ASHPs operate with a baseline SPF of 2.5 , in line with the minimum SPF for an ASHP to be classed as renewable under the current EU Renewable Energy Directive, as well as being the minimum SPF for an ASHP to qualify for the UK's domestic renewable heat incentive (RHI) (HM Government, 2018). For hybrid ASHP systems, SPFs reported in field trials (BEIS and Element Energy, 2017), also varied greatly ranging from 2.5 to 4.0 , with an average of 3.1. Therefore, for this study it is assumed that the ASHP as an element in a hybrid system operates with a baseline SPF of 3.1. This conservative approach as to what can be practically achieved in the near-term is appropriate, and is borne out by field trial data where lower than expected SPFs are seen. However, SPF is a key parameter, and it is acknowledged that with the right combined policy interventions higher SPFs could be seen. Therefore, a sensitivity analysis is carried out in Section 4.2 to explore this variable for all cases.

The UK Treasury's Green Book ${ }^{10}$ (BEIS, 2019c) is used here for annualised data projections for retail prices and carbon intensities of energy sources from the base year 2020 to cover the study period of 20 years.

To account for price differences between standard and timeof-use tariff electricity use for electrical resistive heating, projections for peak and off-peak time-of-use tariff electricity retail prices are made. These are derived by reflecting the percentage price changes for projected standard tariff electricity

\footnotetext{
${ }^{9}$ Seasonal Performance Factor (SPF) is a calculation used to define heat pump efficiency. It is the amount of heat produced by the system compared with the amount of electricity consumed over a year which accounts for seasonal variances of external ambient temperature that impacts efficiency. A given SPF is therefore only directly comparable between technologies for areas with similar annual climate variations.

${ }^{10}$ The Green Book data is the result of various modelling activities (BEIS, 2019c). For example, an electricity generation dispatch model (DECC, 2012) and the

UK MARKAL model (Kannan et al., 2007) were used to generate emissions factors for electricity supply to account for changes in the electricity generation mix.
} 

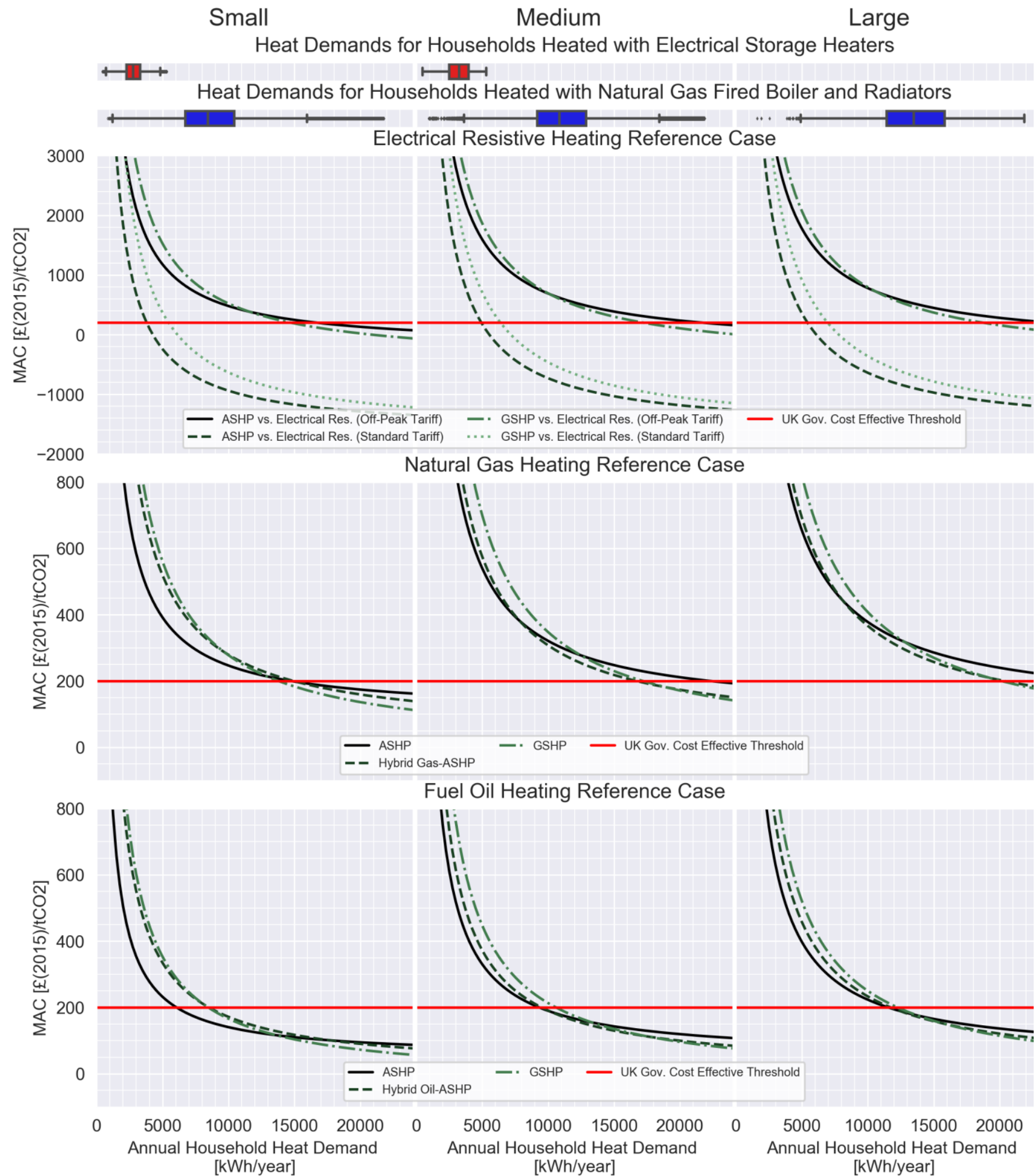

Fuel Oil Heating Reference Case

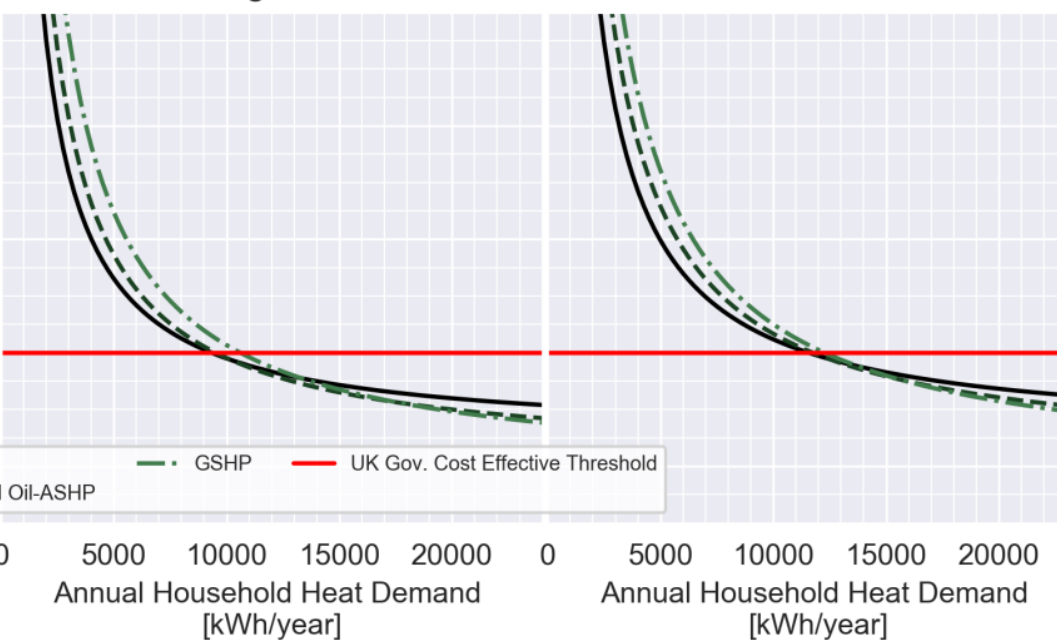

Figure 4 Baseline MAC results for systems priced for a typical small (left column), medium (middle column), and large (right column) size UK dwellings. More specifically the graphs show the difference in cost between mitigating technologies and the reference technologies, divided by the carbon emissions reductions achieved, for a given annual heat demand value. The MAC results are also displayed separately by reference heating option, with the top row of graphs showing MAC results for electrical resistive heating, middle row for natural gas-fired heating and the bottom row for fuel oil-fired heating.

retail prices onto current averages for peak and off-peak timeof-use tariff retail prices (BEIS, 2019d).

The authors in (Kesicki and Strachan, 2011) discuss the importance of choosing the appropriate discount rate. They outline that many MAC studies use a discount rate of around $3.5 \%$, which is recommended as the social discount rate by the UK Government (HM Treasury, 2018). Discounting in the public sector allows costs and benefits with different time spans to be compared on a common "present value" basis. The public sector discount rate adjusts for social time preference, defined as the value society attaches to present, as opposed to future, consumption, and so is used here. The discount factor (DF) for a given year is determined by equation (5) as per the method described in (HM Treasury, 2018).

\section{MAC Results}

\subsection{MAC Results for Baseline Technology Characteristics}

The baseline MAC results (i.e. for baseline technology characteristics and the UK Government central energy prices scenario) are displayed in Figure 4 for the mitigating technologies (standalone and hybrid HP systems) relative to the reference heating technologies when used in a typical small, 


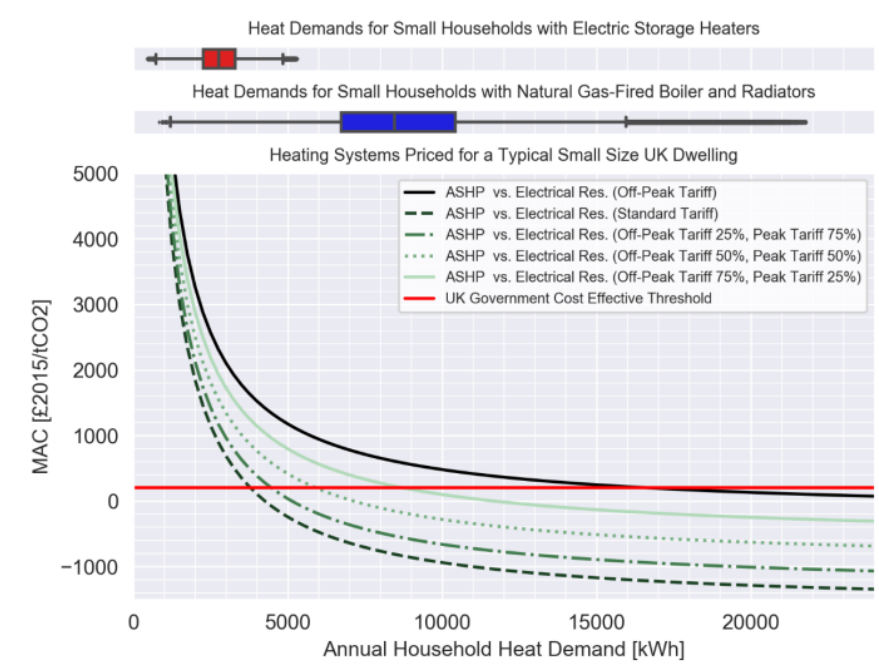

Figure 5 MAC results for a standalone ASHP system relative to electrical resistive heating with varying assumptions for the electricity tariff used to service heat demand.

medium and large size UK dwelling. Above the graphs displaying MAC values for each case, the representative annual end-use heat demand ranges for existing households are shown for each relevant main heating technology. By aligning the heat demand ranges for the heating types with the associated MAC values, the cost-effectiveness of a given abatement measure can be estimated. Analysis into dwelling characteristics for heating types (Appendix B) shows that households heated with electric storage heaters have a maximum of 4 heated rooms, and so the distribution of heat demands for households heated with electric storage heaters are not applicable for the MAC values derived for heating systems priced for a typical large size UK dwelling.

The results in Figure 4 illustrate that the MAC for all mitigating options is sensitive to the level of heat demand, with the values changing significantly for low heat demands. This is because at low demand values, the difference in capital cost between the reference and mitigating technology has a greater relative impact on the resulting MAC value compared to the other determining factors.

Overall, the MAC results over the heat demand estimates for all dwelling sizes indicates that it is likely that - assuming no rebound - retrofitting HP systems into existing households does not represent a negative MAC option. Based on the baseline MAC results, if the heat demands for households heated with fuel oil-fired heating systems are comparable to that of households with natural gas-fired heating, then households with fuel oil-fired heating systems are likely to be the most costeffective candidates for HP uptake - specifically, standalone ASHP systems for the households with low heat demands, and either GSHP or hybrid Oil-ASHP systems for larger dwellings with high heat demands.

For existing households heated with electric storage heaters, the cost-effectiveness of retrofitting a standalone ASHP system depends heavily on the electricity tariff used for electrical resistive heating to service the heat demand. As discussed in Section 2, many households with electric storage heaters appear to be restricting their energy consumption due to the relatively high unit cost of thermal energy delivered for heating purposes. Moreover, some occupants may be using varying amounts of peak time-of-use electricity, or even using a standard tariff despite having storage heaters. Figure 5 demonstrates the impact on the MAC for varying proportions of time-of-use tariff as well as the use of a standard tariff used by households with electric storage heaters. If households heated with electric storage heaters had comparable heat demands to that of similar dwellings heated with a natural gas-fired boiler and radiators then, for the cases where peak time-of-use electricity is used, a number of additional households represent negative MAC options for standalone ASHP uptake. This is an important finding particularly if the comfort requirements of existing households with electric storage heaters are currently not being met, which may be more likely for households with relatively high proportional energy expenditures.

\subsection{Sensitivity Analysis}

Historical technology learning curves (or experience curves), such as those for electrical storage systems (Schmidt et al., 2017) and those for renewable wind and solar PV electricity generation (IRENA, 2018), tell us that with greater cumulative capacity deployment levels over time there are reductions in cost. The evidence from field trials and market analysis for HPs in the UK, as documented in (BEIS and Element Energy, 2017; Energy Saving Trust, 2013) demonstrates that there are varying reports for technology cost and performance, as well as multiple system configurations and control strategies. As mentioned in the Introduction, many assumptions are made for current and future heating technology characteristics in energy models. The aim of the analysis here is to explore the sensitivity of the MAC with regards to assumptions made for technology variables. In the UK, natural gas and fuel oil fired heating systems are well established, and it is expected that the cost and performance of new systems that meet the latest standards will largely remain the same. Therefore, the sensitivity of technology variables for HPs are only assessed here. See Appendix F for figures displaying the results for the sensitivity analysis.

The results demonstrate that, for a reduction in HP associated CAPEX, the MAC values decrease by a greater relative amount for households with low heat demands than that observed for higher heat demands. For an increase in performance for HPs, the MAC decreases by a greater relative amount for households with high heat demands than that observed for low heat demands. These trends make sense as differences in CAPEX have an increasing influence on the MAC as demand decreases, whereas differences in fuel consumption costs have an increasing influence on the MAC as demand increases.

Hybrid HP systems display some interesting sensitivities. Figure F.7 demonstrates that if the HP, as an element in a hybrid system, services less heat demand, then the MAC considerably increases. Furthermore, under the conditions of both improved performance and CAPEX reductions for HPs, the MAC for hybrid HP systems does not decrease by as much as that observed for standalone HP systems. This is due to the presumed constant characteristics of the boiler element (for both natural gas and fuel oil fired boilers) in the hybrid system.

Statistics for the UK's renewable heat incentive (RHI) scheme (BEIS, 2020a) are provided for accredited HP installations ${ }^{11}$. The maximum SPF values recorded are 4.0 for ASHP systems and 4.6 for GSHP systems (although, it is not clear if hybrid systems are included). These values are $60 \%$ and $20 \%$ higher than the baseline values used here for an ASHP and GSHP system respectively. The CCC assume in their Net Zero analysis (CCC, 2019b) that ASHP costs could reduce by around $11 \%$ (conditions permitting). Based on the sensitivity analysis results, and considering that the technology characteristics of HPs mirror these maximums, then it is still likely that all abatement options would have MAC values above zero. There would however be a greater number of households that would

\footnotetext{
${ }^{11}$ The SPF values are obtained from the MCS certificate for each domestic installation. MCS refers to the Microgeneration Certification Scheme. It is a requirement of the Domestic RHI scheme that all heating systems are certified by MCS (MCS, 2020).
} 
appear 'cost effective' based on the UK Government costeffective threshold of $£ 200 / \mathrm{tCO} 2$.

The sensitivity analysis demonstrates that the MAC is highly sensitive to technology assumptions as well as heat demand. Given the relative similarity between MAC values for the different abatement options, it is therefore clear that relying solely on the results from least-cost optimisation energy systems models for policy making, particularly models with a high degree of aggregation, could mean that some mitigating options are unfairly overlooked.

A note must be made on other factors that impact the MAC. Here a discount rate of $3.5 \%$ is used. A higher discount rate means that any potential future operational cost savings carry less weight. In addition, Net Present Value, as used here, is commonly used in long-term planning studies. Other methods could increase or decrease the cost-effectiveness of HP systems relative to reference options. Another long term planning method is equivalent annual cost (EAC) (Sachs et al., 2019). However, there is uncertainty with regards to the exact design or technical life of heating technologies used to annualise costs.

\section{Conclusions \& Policy Implications}

5.1 There is potential for the end-use heat demands of households heated with electric storage heaters to double, as per the direct rebound effect, when transitioning to heating with similar operating costs to that of natural gasfired heating

The analysis in Section 2 reveals that among households with similar building characteristics and with the same type of heating system, those occupied by social demographic groups with higher levels of deprivation tend to have lower end-use heat demands. For similar building characteristics and social demographics, households heated with a natural gas-fired boiler and radiators have on average double the end-use heat demands as households heated with electric storage heaters. It is likely that many households are restricting their energy consumption due to the relatively high unit cost of thermal energy delivered by electrical resistive heating, and demonstrates that demand is sensitive to cost differences for heat provision in the residential sector.

The findings suggest that there is realistic potential for the heat demands for many households heated with electric storage heaters to double, as per the direct rebound effect, if access to a heating option with similar costs to natural gas-fired heating is gained. This means that levels of actual energy consumption for certain households adopting low carbon heating could be different from expected levels of energy consumption. Therefore, the use of electrical resistive heating options, such as electric storage heaters, should be examined on a basis of affordability and ability to satisfy comfort requirements. This is particularly relevant for households that have relatively high proportional energy expenditures - either made higher by lower energy efficient homes, or relatively higher by a lower income or competing costs.

Furthermore, this has the potential to undermine the contribution of the residential heat sector to national decarbonisation targets, as any reduction in energy intensity achieved through increasing the roll-out of heat pumps (HPs) could be opposed by an increase in residential energy use, particularly if targeted at fuel poor households. However, it is important to stress that the value case for mitigating options such as HPs, extends beyond simply reducing emissions and energy consumption, as there is potential to improve comfort, welfare and health standards (Belaïd et al., 2018; Clinch and Healy, 2003; Kelly et al., 2016).
Smart meters, automated control systems and enhanced billing are proven policy options that can reduce non-essential energy consumption for water and space heating, and thus mitigate non-beneficial rebound effects (Font Vivanco et al., 2016; Seebauer, 2018; Vellei et al., 2016). Further, Time-ofUse tariffs (for which, there are multiple options available to UK domestic customers, as evident on regulator approved price comparison sites (Ofgem, 2020)), also provide an opportunity for rebound mitigation. However, research has shown in (Kelly et al., 2014) that a large thermal buffer is required to sufficiently shift HP load. The same research also strongly indicates that more sophisticated load management strategies other than simple tariff based approaches are required to obtain the full benefits of HPs.

The weakness with the comparative approach used here is that it is not practically possible with the data available to enact full control over the study sample and account for the vast array of variables, such as those related to the exact heating regimes executed by occupants (i.e. internal temperature, number of heating hours and tariffs used). Furthermore, households with electric storage heaters only account for around 5\% of the housing stock. Therefore, building on the findings from this study, a comprehensive economic appraisal, based in a similar vein to the work in (Belaïd et al., 2018), would provide detailed quantitative evidence on the magnitude of potential demand rebounds for low carbon heating uptake. This further work should aim to capture a high degree of sector heterogeneity.

5.2 The marginal abatement cost (MAC) of heat pump (HP) systems relative to reference heating options is strongly dependent on the level of end-use heat demand and assumptions made for technology variables, meaning a 'one size fits all' approach is unlikely to enable costeffective emissions reductions in the residential sector

The UK Government aspires to upgrade the energy performance of 17 million homes to a minimum energy performance certificate (EPC) rating of $\mathrm{C}$ - on a scale of $\mathrm{A}$ (best) and G (worst) - is realised where "practical", "costeffective" and "affordable" (BEIS, 2017a). For this, they define that abatement measures for households are "cost-effective" when below the threshold identified as lying between $£ 100$ $£ 200 /$ tCO2e (UK Parliament, 2019).

For baseline technology characteristics modelled, the analysis in Section 4 shows that for HP uptake, it is likely that the most cost-effective abatement options at present is to replace fuel oilfired heating in off-gas grid homes. Over the range of UK household heat demands this varies in cost between $£ 100$ $200 / \mathrm{tCO} 2$, where it is more cost effective to implement a standalone air-source heat pump (ASHP) system in small dwellings with low heat demands, and either a ground-source heat pump (GSHP) or hybrid ASHP system in larger dwellings with higher heat demands. For the majority of existing UK households, i.e. households heated with natural gas-fired heating, the abatement cost for HP uptake is likely to be above $£ 200 / \mathrm{tCO} 2$.

For existing households with electric storage heaters, the MAC values for HP uptake also depends heavily on the electricity tariff used for electric storage heating to service heat demand. Once the potential direct rebound effect is taken into account for these households, the number of cost-effective abatement options increases, with a small number potentially representing negative MAC options - i.e. reducing both carbon emissions and overall costs. The value case for HPs therefore extends beyond emissions reductions, as - for some cases - HPs could also permit access to lower cost overall heat supply. 
The analysis demonstrates that the MAC is highly sensitive to heat demand and technology assumptions. Given the relative similarity between MAC values observed for the different abatement options, it is therefore clear that relying solely on the results from energy systems models for policy making, particularly models with a high degree of sectoral aggregation, could mean that some mitigating options are unfairly overlooked. It is recommended that approaches used to assess decarbonisation efforts should utilise a suite of tools that account for within-sector diversity and have broad definitions of the benefits for which options are measured against. This will allow for more tailored and effective policy interventions in the residential sector.

\subsection{The value case for heat pumps and the case for policy support is interdependent with interventions taken to increase building energy efficiency}

There are complex trade-offs between a number of factors that determine overall costs and emissions produced for a given heating option. Such factors for HPs can include (but are not limited to); the capacity, performance and control strategy of the system, along with dwelling thermal efficiency and heat demand (in terms of both annual total and daily profile). Heat pumps typically operate at a lower temperature compared to commonly in-use heating options, such as natural gas-fired heating, and for that reason in order to satisfy comfort requirements they are better suited to dwellings that have appropriate energy efficiency measures.

However, the analysis in Section 4 reveals that as heat demand decreases, the difference in capital cost between the reference and mitigating technology has a greater relative impact on the resulting MAC value. Therefore, if a reduction in heat demand is realised for the majority of existing UK dwellings (i.e. through implementing dwelling energy efficiency measures), the abatement cost for HP retrofit will likely increase unless systems are sized appropriately and necessary performance levels for HPs are also realised to compensate for this. This means that there is also potential for some households with relatively low levels of energy consumption to continue the use of existing heating types with low capital costs, such as electric storage heaters (in the near term at least), where this is proven to not be compromised by comfort, welfare and health issues.

In the UK, energy saving materials (ESM) for residential homes, such as insulation and low carbon heating, previously qualified for a reduced VAT rate of 5\% (conditions permitting) compared to the standard rate of $20 \%$ (HM Revenue \& Customs, 2014). As of $1^{\text {st }}$ October 2019 new rules ${ }^{12}$ for the reduced rate of ESMs came into force essentially increasing the VAT for ESMs for typical households (UK Government, 2019). Based on the analysis in Section 4, this policy could decrease the cost-effectiveness of HPs for emissions reductions relative to reference heating options. Further to this, the decision made by householders, or other actors involved in capital expenditure, whether or not to invest in alternative heating options will generally not involve a long-term economic analysis. Instead, decisions are likely to be based on typical capital and operational costs at the time of purchase that are weighted more towards upfront costs.

It is recommended that policymakers should re-examine the VAT rate for ESMs as an increase in upfront costs could discourage the uptake of low carbon heating. Continuation of existing financial incentives in order to 'seed' development of the market and, in the medium term, reduce costs and achieve improved performance, and build public confidence in the technology is critical in overcoming the 'lock-in' barrier of natural gas-fired heating. Acceptance of the abatement costs for residential heating, as presented in Section 4 for HP systems relative to reference heating options, is necessary, which are ultimately due to the current scale of gas distribution networks and the relatively low unit cost per thermal energy delivered by natural gas-fired heating systems.

This study does not address other important topics in this policy area, such as energy security of supply, the debate regarding electrification vs. hydrogen for heating, the role of network infrastructure and price volatility of primary energy. The potential role of hydrogen for heating, in particular, remains uncertain (IET, 2019). It is also worth noting that the UK's dependency on importing natural gas has been increasing over the years, and now accounts for over half of all natural gas supply (BEIS, 2020b). According to National Grid (the UK's transmission network operator), this could further rise to a level of around $78 \%$ by 2035 if the level of UK shale gas production is zero (National Grid, 2017). Therefore, shifting to electrification in parallel with a further decarbonised and diversified power system could allow for lower abatement costs for heating uptake and an increase in the security of supply.

\subsection{A national heat strategy should consider diversity, localised requirements, spatial challenges, and the requirements and preferences of actors involved in capital and/or operational expenditure}

Heat pumps represent a key technology towards decarbonising the heat sector in the UK. However, this study shows that the abatement cost and system suitability varies across the housing stock. In turn, policy must consider within-sector diversity and localised requirements/opportunities, as well as address knowledge-action gaps, value-action gaps, attitude-action gaps and/or intention-action gaps (Frederiks et al., 2015). For example, the Scottish Government's assistance to Local Authorities in creating Local Heat and Energy Efficiency Strategies (LHEES) (Scottish Government, 2019) provides a framework for zoning of potential local heat solutions, predicated on socio-economic outcomes (i.e. all co-benefits such as health, quality of life etc.), alongside demand reduction and decarbonisation. This need for short-term zoning, however, assumes that any such system is a technology and price-taker, and so such local decisions must be made independently from potential wider-scale supply-side transitions. This means that the 'optimal' technology decision may require joint planning of a local energy system and the supply side, but in reality, the local system planner only has control over their domain and must select the subset of technologies that use supply-side vectors available to them.

Achieving deep decarbonisation in domestic buildings, and thus displacing unabated natural gas use by 2050 , is one of the greatest challenges which requires strategic decisions to be made by the mid-2020s (CCC, 2019b). Given the significant cost and lifetimes of energy infrastructure, research will need to identify how, on a least-regret basis, household comfort requirements can be met in line with a net-zero GHG emissions target that avoids 'locking-in' the UK to a costlier and less effective decarbonisation pathway. This is not only a spatial challenge but also a timing challenge that involves many

\footnotetext{
${ }^{12}$ These new rules (UK Government, 2019) mean that a reduced rate will only remain available to "qualifying persons" who meet a 'social policy test' (60 years or over and in receipt of benefits or a 'relevant housing association'). For all other households, the reduced rate remains only when the value of the materials does not exceed $60 \%$ of the consumer cost (excluding VAT) of installing the energy saving measure. When the materials cost is $60 \%$ of the total cost (excluding VAT), the installation costs will have a 5\% VAT rate - but the more significant capital cost will now attract VAT at $20 \%$.
} 
stakeholders. The authors recommend that future research is necessary to improve systems-based approaches (i.e. utilising energy systems models) to inform national scale heat policy that better represents the diversity and demand elasticity within the residential sector. A key aspect of this will be capturing the diversity of requirements and preferences of actors involved in capital and/or operational expenditure that does not overlook key outliers in the system, such as fuel poor and vulnerable households.

\section{Acknowledgements}

JF is supported by the Centre for Doctoral Training in Future Power Networks and Smart Grids, under Engineering and Physical Sciences Research Council (EPSRC) Grant No. $\mathrm{EP} / \mathrm{L} 015471 / 1$. The contribution from $\mathrm{GH}$ and $\mathrm{KB}$ was undertaken within Phase 3 of the UK Energy Research Centre (UKERC), supported by the UK Research Councils under Natural Environmental Research Council award NE/G007748/1 and EPSRC Grant No. EP/L024756/1.

\section{Appendix A. Method for Deriving Heat Demand Estimates}

\section{A.1. Estimating End-Use Heat Demand Based on Metered Consumption Data}

Annual household heat demand estimates for the UK are derived by converting actual metered energy consumption data, sourced from the sub-national electricity (BEIS, 2019a) and gas (BEIS, 2019b) consumption meter statistics, into thermal energy assumed to represent the end-use heat demand of a household. Dwelling and heating system characteristic data is sourced from Energy Performance Certificates (EPC) for England and Wales (Ministry of Housing Communities \& Local Government, 2018).

For EPC data, full address location information is available for households in England and Wales. The highest spatial resolution of energy consumption statistics is at full postcode level where an average meter value is provided for the years 2016 and 2017. For these years, the UK annual (Figure A.1) and winter (Figure A.2) temperature averages were slightly above the long-term average from 1981 to 2010 (Met Office, 2019). For each full postcode where data is available for both years, an average consumption value for natural gas and electricity ${ }^{13}$ was found over the two years. As a full postcode in the UK has an average of 15 households (typically ranging between 1 and 100), a high degree of spatial resolution is used in this study.

The annual heat demand for natural gas heated households is estimated based on making the following assumptions; the calorific value of natural gas is uniform throughout GB; the average existing natural gas-fired boiler efficiency is now $85 \%$ (DECC, 2013); and 2\% of household natural gas consumption is used for cooking (DECC, 2014). Annual household heat demand is derived for all postcodes where natural gas heating is present. Once found, the total number of households heated with a natural gas-fired boiler and radiators in a postcode (as determined from EPC data) is then used with the average heat demand estimate for the corresponding postcode to find the diversity of heat demands throughout GB.

For households heated with electrical resistive heating, estimating heat demand based on electricity consumption is more complex as there are many other household uses of electricity. The difference in energy consumption between the Economy 7 time-of-use tariff meters and standard meters in postcodes throughout the UK provides an indication of the amount of additional electricity a household uses for space and

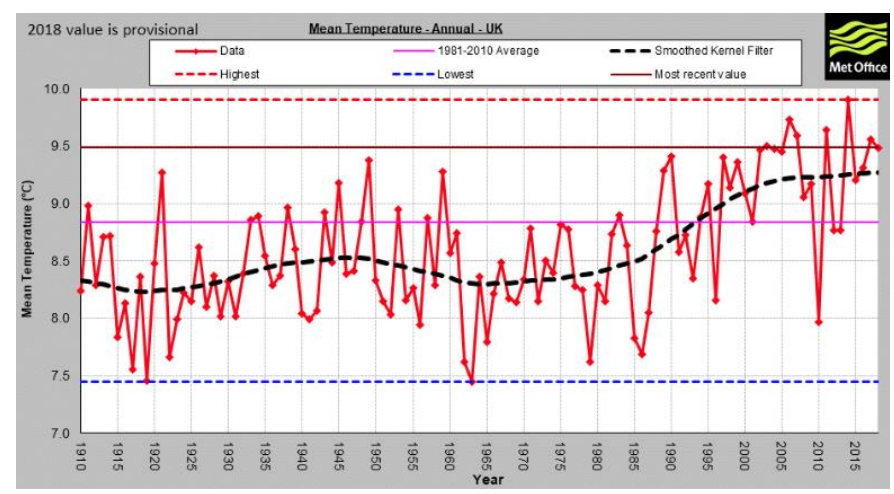

Figure A.1. Annual Mean Temperature Data for the UK (Met Office, 2019)

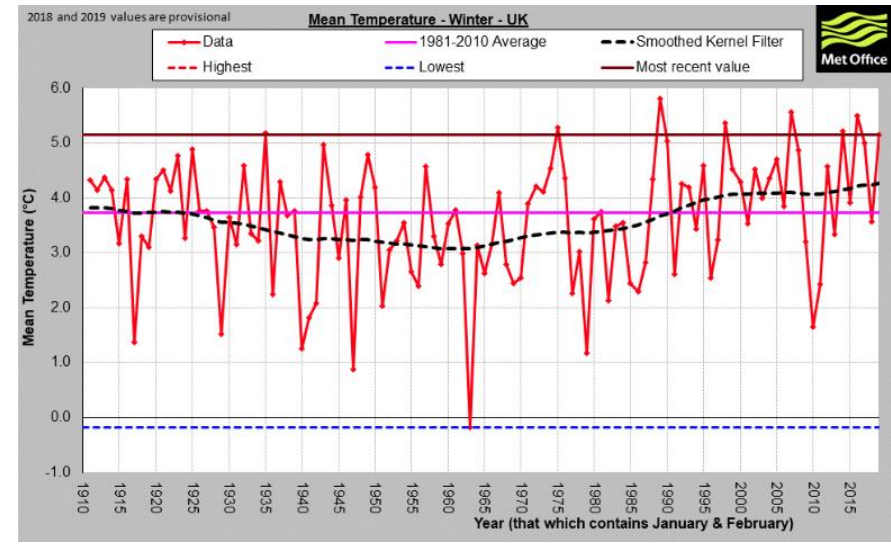

Figure A.2. Annual Mean Winter Temperature for the UK (Met Office, 2019)

water heating. This difference was found to be around $30 \%$ of average Economy 7 meter consumption.

The British gas and electricity industry regulator Ofgem provides Typical Domestic Consumption Values (TDCVs) that are industry standard values for annual gas and electricity usage of typical domestic consumer types. In Ofgem's most recent revised TDVCs (Ofgem, 2017), an average day/ night split for Economy 7 meter consumption is defined as $58 \%$ and $48 \%$ peak/off-peak. Accounting also for a small amount of peak time use of electrical resistive heating due to non-optimal system use (Ofgem, 2015), it is assumed that 50\% of total Economy 7 electricity meter consumption is a reasonable estimate for electricity used for space and water heating, and so is used here.

As carried out for natural gas heated homes, heat demands are found for all postcodes in GB that have Economy 7 meters. Once found, the total number of households heated with electric storage heaters in a postcode (as determined form EPC data) is then used with the average heat demand estimate for the corresponding postcode to find the diversity of heat demands throughout GB.

It is described in (BEIS, 2018b) that the sub-national gas and electricity consumption meter datasets include some meter points that have low or no consumption. These meter points represent sites that have been vacant for a short period of time, and sites that have been de-energised partway through the year. Along with this, EPC data includes invalid or unreliable entries, as discussed in (CCC, 2019c). Therefore, the data sets are first cleaned using the interquartile range (IQR) method to remove false and non-relevant data. The IQR is a measure of the dispersion similar to standard deviation or variance, but more robust against outliers. Using this method, data was considered an outlier, and then removed, if the value is above or below the middle $50 \%$ of data (IQR) by more than half of the IQR value.

\section{A.2. Normalising Heat Demand and Obtaining Dwellings with Similar Properties}

\footnotetext{
${ }^{13}$ For sub-national electricity consumption statistics, data is provided for standard and economy 7 meter types. Data for both meter types are used and kept separate here.
} 
Normalising the heat demand estimates as the thermal energy per square meter floor area delivered by heating systems over a year, and applying filters to obtain dwellings with similar characteristics, allows households to be compared on a similar basis. Many factors contribute to a household's thermal efficiency. According to (DECC, 2013), a large amount of heat loss is via external walls. A significance test carried out on dwelling efficiency properties demonstrates that there is a positive correlation between all dwelling efficiency properties. As shown in Table A.1 these relationships are strongest for flats where it is likely that flats with good thermal efficiency of walls (i.e. cavity insulated walls) are also likely to have good thermal

Table A.1.

Spearman Correlation Matrix Test Results for Dwelling Energy Efficiency Properties.

\begin{tabular}{|c|c|c|c|c|c|c|}
\hline & & Walls & Windows & Lighting & Roof & $\begin{array}{l}\text { Sample } \\
\text { Size } \\
\text { (million) }\end{array}$ \\
\hline \multirow[t]{3}{*}{ Flat } & Walls & & 0.531 & 0.226 & & 3.985 \\
\hline & Windows & 0.531 & & 0.227 & & \\
\hline & Lighting & 0.226 & 0.227 & & & \\
\hline \multirow[t]{4}{*}{ Bungalow } & Walls & & 0.206 & 0.163 & 0.318 & 1.344 \\
\hline & Windows & 0.206 & & 0.113 & 0.181 & \\
\hline & Lighting & 0.163 & 0.113 & & 0.186 & \\
\hline & Roof & 0.318 & 0.181 & 0.186 & & \\
\hline \multirow[t]{4}{*}{ Maisonette } & Walls & & 0.372 & 0.118 & 0.408 & 0.248 \\
\hline & Windows & 0.372 & & 0.137 & 0.269 & \\
\hline & Lighting & 0.118 & 0.137 & & 0.095 & \\
\hline & Roof & 0.408 & 0.269 & 0.095 & & \\
\hline \multirow[t]{4}{*}{ Terrace } & Walls & & 0.328 & 0.123 & 0.39 & 4.167 \\
\hline & Windows & 0.328 & & 0.141 & 0.277 & \\
\hline & Lighting & 0.123 & 0.141 & & 0.163 & \\
\hline & Roof & 0.39 & 0.277 & 0.163 & & \\
\hline \multirow[t]{4}{*}{$\begin{array}{l}\text { Semi- } \\
\text { Detached }\end{array}$} & Walls & & 0.299 & 0.162 & 0.338 & 3.203 \\
\hline & Windows & 0.299 & & 0.151 & 0.249 & \\
\hline & Lighting & 0.162 & 0.151 & & 0.191 & \\
\hline & Roof & 0.338 & 0.249 & 0.190 & & \\
\hline \multirow[t]{4}{*}{ Detached } & Walls & & 0.472 & 0.207 & 0.423 & 1.983 \\
\hline & Windows & 0.472 & & 0.228 & 0.369 & \\
\hline & Lighting & 0.207 & 0.228 & & 0.227 & \\
\hline & Roof & 0.423 & 0.369 & 0.227 & & \\
\hline \multirow[t]{2}{*}{ Key } & -1 & -0.8 & -0.6 & -0.2 & 0 & \\
\hline & 0.2 & 0.4 & 0.6 & 0.8 & 1 & \\
\hline
\end{tabular}

efficiency of windows (i.e. double glazing). Therefore, for brevity and to maintain a significant data sample size, dwellings are segregated here based on dwelling type, wall characteristics as well as by the number of rooms heated in a household.

The findings in Section 2 suggest that the normalised heat demands for households heated with a natural gas-fired boiler and radiators are, on average, more than double compared to that of households with electric storage heaters. To support these findings the approach used to filter households is validated here, i.e. to check that the filtering method used does not overlook additional dwelling characteristics that have a greater influence on the energy consumption needed to satisfy heat demand. For this, the EPC dataset for England and Wales is again consulted. The following relevant estimates for domestic EPC records are provided:

- Total household annual energy consumption $\left[\mathrm{kwh} / \mathrm{m}^{\wedge} 2\right]$

- Annual cost of heating property [£]

- Annual cost for hot water [£]

As shown, only cost estimates are provided for heat only energy use. Given the different tariffs used for EPC assessments (BRE Group, 2012), it is more difficult to use this data as the basis for comparing households with different heating types.

EPC estimated 'total household annual energy consumption' accounts for non-heating uses of energy such as lighting. However, it is believed that this data still provides a good evidence base to assess if there are any additional dwelling characteristics that are overlooked by the filtering method.

Table A.2.

EPC estimated total annual household energy consumption per square meter floor area derived using the SAP method (BRE Group, 2012). Results displayed are for flats heated with either electric storage heaters or a natural gas-fired boiler and radiators.

\begin{tabular}{|c|c|c|c|c|c|}
\hline & \multirow{2}{*}{$\begin{array}{l}\text { Number of } \\
\text { Heated } \\
\text { Rooms }\end{array}$} & \multicolumn{2}{|c|}{$\begin{array}{l}\text { Households Heated with Electric } \\
\text { Storage Heaters }\end{array}$} & \multicolumn{2}{|c|}{$\begin{array}{l}\text { Households Heated with Natural Gas- } \\
\text { Fired Boiler and Radiators }\end{array}$} \\
\hline & & $\begin{array}{l}\text { Average Annual } \\
\text { Energy Consumption } \\
\text { Per Meter Square Floor } \\
\text { Area }\left[\mathrm{kWh} / \mathrm{m}^{\wedge} 2\right]\end{array}$ & $\begin{array}{l}\text { Data } \\
\text { Sample Size }\end{array}$ & $\begin{array}{l}\text { Average Annual Energy } \\
\text { Consumption Per Meter } \\
\text { Square Floor Area } \\
{\left[\mathrm{kWh} / \mathrm{m}^{\wedge} 2\right]}\end{array}$ & $\begin{array}{l}\text { Data } \\
\text { Sample } \\
\text { Size }\end{array}$ \\
\hline \multirow{4}{*}{$\begin{array}{l}\text { Flats with } \\
\text { Cavity Insulated } \\
\text { Walls }\end{array}$} & 1 & 490.65 & 12,053 & 266.98 & 8,676 \\
\hline & 2 & 394.10 & 78,838 & 224.79 & 147,320 \\
\hline & 3 & 371.52 & 63,863 & 225.16 & 190,068 \\
\hline & 4 & 375.48 & 4,866 & 251.67 & 35,494 \\
\hline \multirow{4}{*}{$\begin{array}{l}\text { Flats with Solid } \\
\text { Un-insulated } \\
\text { Walls }\end{array}$} & 1 & 837.40 & 3,157 & 417.27 & 6,802 \\
\hline & 2 & 755.36 & 11,256 & 415.54 & 66,717 \\
\hline & 3 & 720.72 & 5,229 & 437.69 & 76,332 \\
\hline & 4 & 817.65 & 762 & 509.17 & 23,418 \\
\hline
\end{tabular}
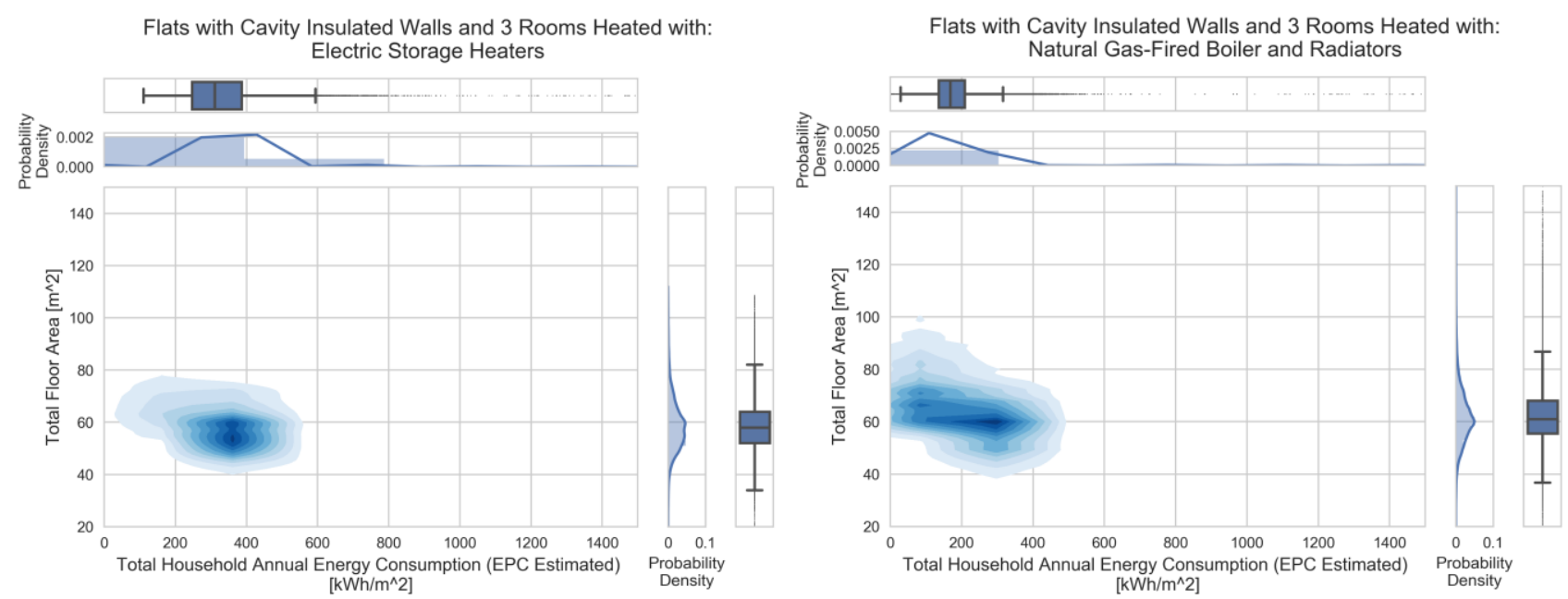

Figure A.3. Distribution of EPC estimated total household energy consumption for flats with cavity insulated walls and three rooms heated with either electrical storage heaters (left graph) or a natural gas fired boiler and radiators (right graph). 
Please see Table A.2 that displays average values for EPC estimated 'total household annual energy consumption' by dwelling category. Also see Figure A.3 that depicts the distribution of EPC estimates for an example case.

If it is assumed that all households within a category (after filtering to obtain 'similar properties') have identical nonheating uses of energy, and it is also assumed that the conversion efficiency of natural gas-fired heating systems is less than that for electrical resistive heating, then it becomes evident that households with electric storage heaters have higher estimated end-use heat demands. This finding therefore supports the hypothesis that higher costs are the main reason for the difference in end-use heat demands.

\section{Appendix B. Distribution of Dwelling Characteristics by Heating Type}

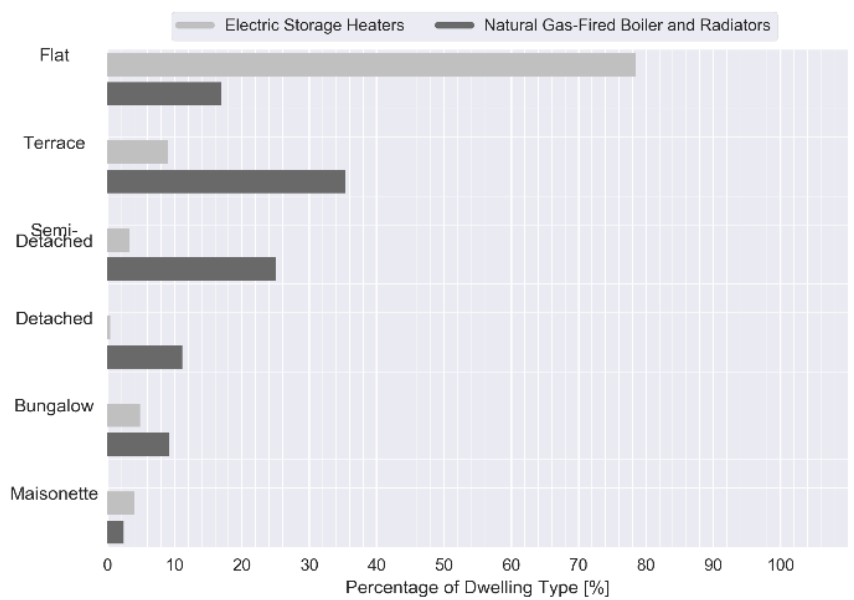

Figure B.1. Showing the percentage of dwelling types for households with either electric storage heaters or a natural gas-fired boiler and radiators. Data is sourced from Energy Performance Certificates for England and Wales (Ministry of Housing Communities \& Local Government, 2018).

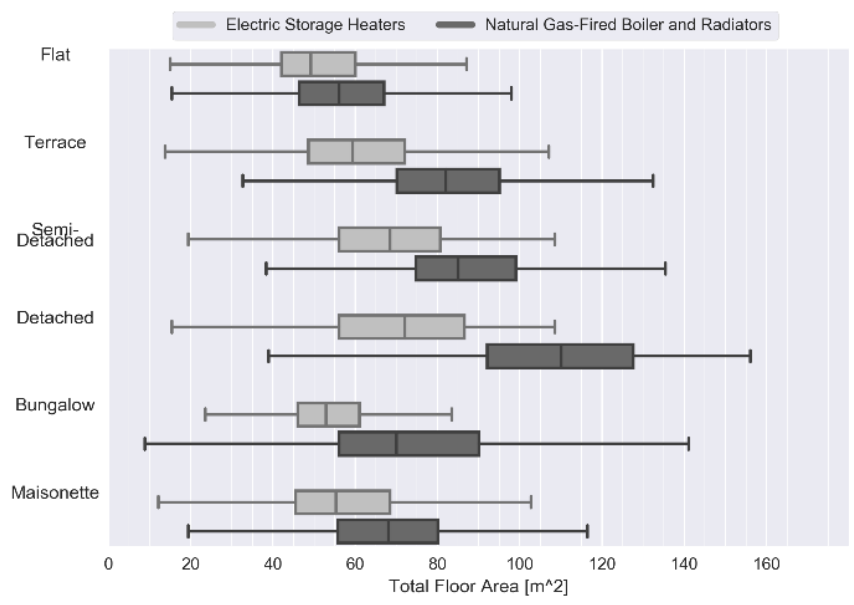

Figure B.2. Showing the distribution of total floor area of households with either electric storage heaters or a natural gas-fired boiler and radiators. Data is sourced from Energy Performance Certificates for England and Wales (Ministry of Housing Communities \& Local Government, 2018).

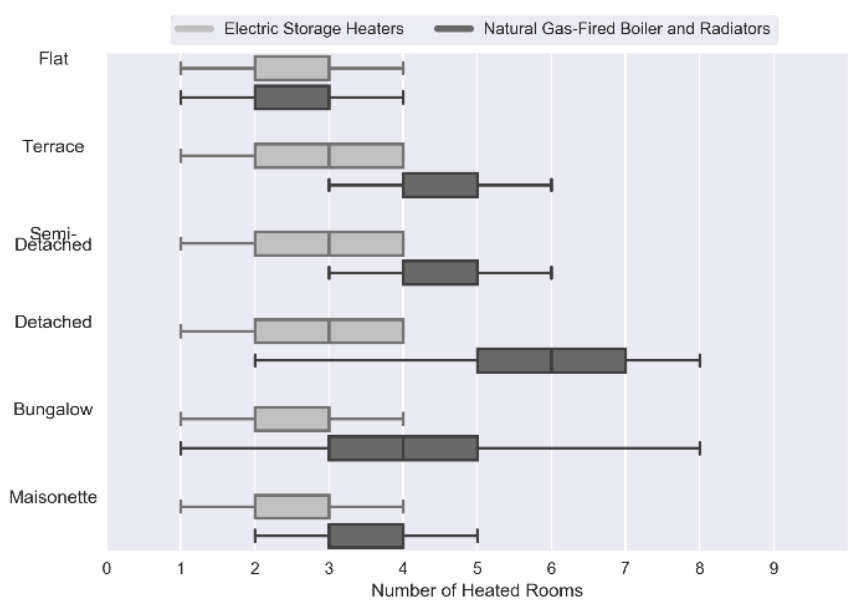

Figure B.3. Showing the distribution of number of heated rooms for households with either electric storage heaters or a natural gas-fired boiler and radiators. Data is sourced from Energy Performance Certificates for England and Wales (Ministry of Housing Communities \& Local Government, 2018).
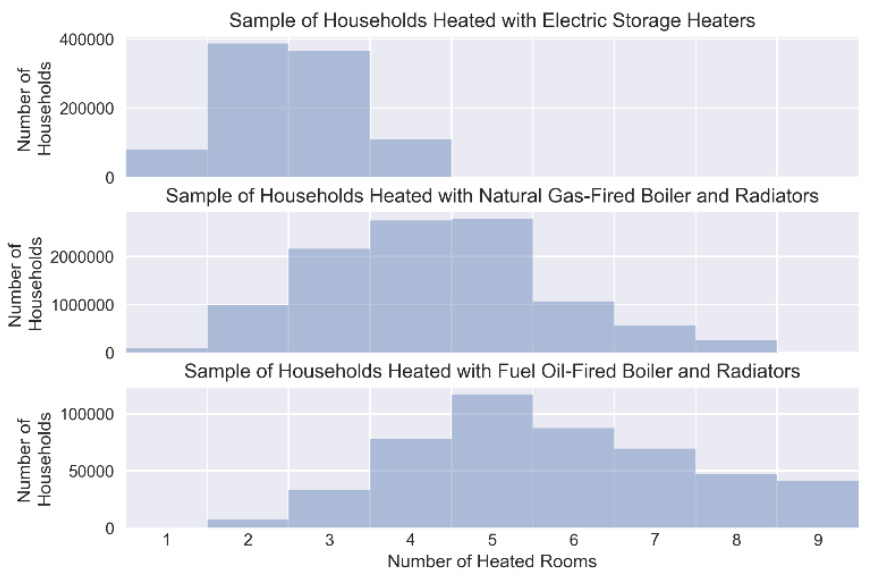

Figure B.4. Showing the distribution of number of heated rooms by main heating type. Data is sourced from Energy Performance Certificates for England and Wales (Ministry of Housing Communities \& Local Government, 2018) 


\section{Appendix C. Correlation Matrix Results for Heat Demand and Socio-Economic and Demographic Variables}

\section{C.1. Dwellings with Cavity Insulated Walls}

Note, see Subsection C.3 for matrix key and socio-economic and demographic variable descriptions.

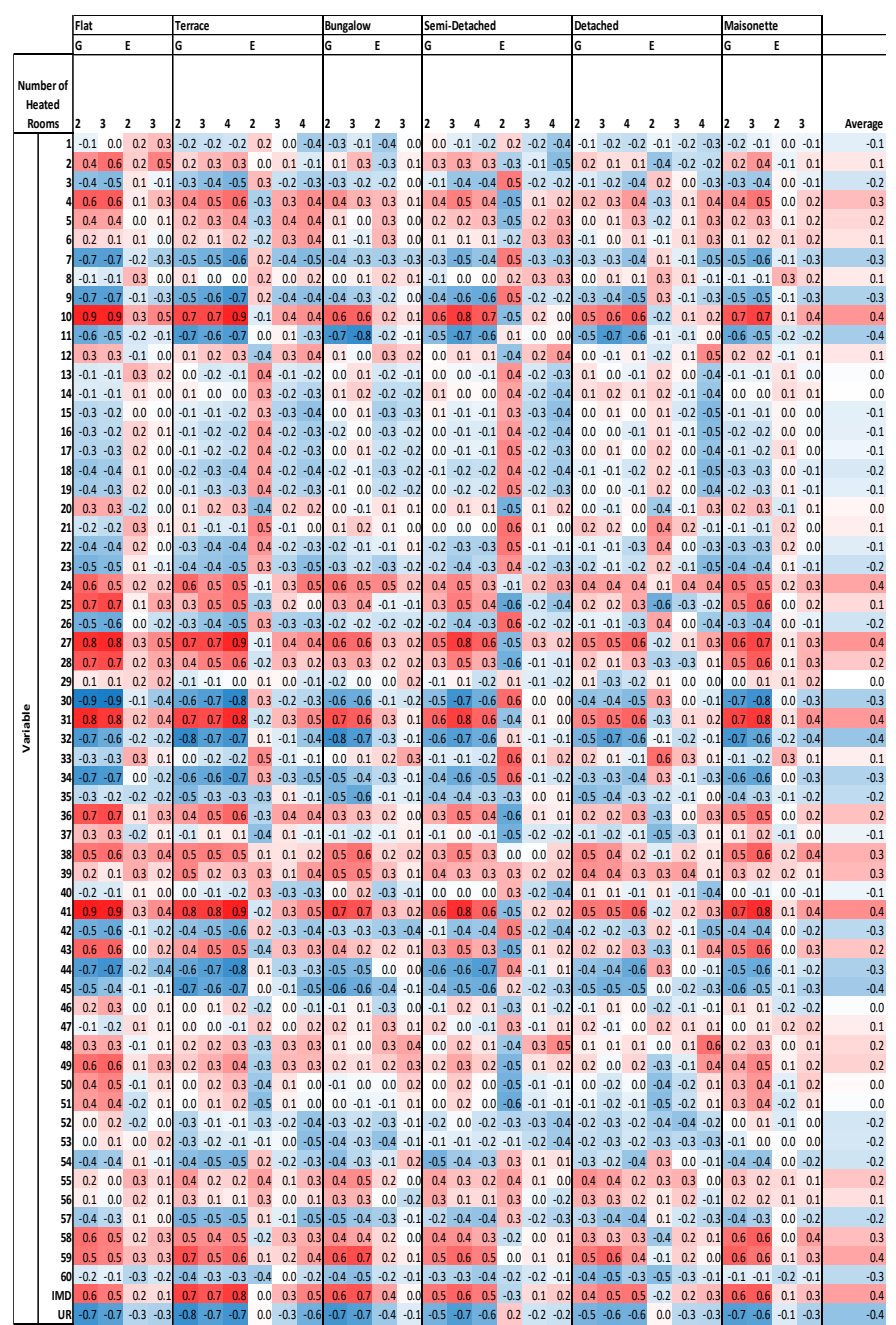

Figure C.1. Spearman Correlation Matrix Test Results for Dwellings with Cavity Insulated Walls.

\section{C.2. Dwellings with Solid Un-Insulated Walls}

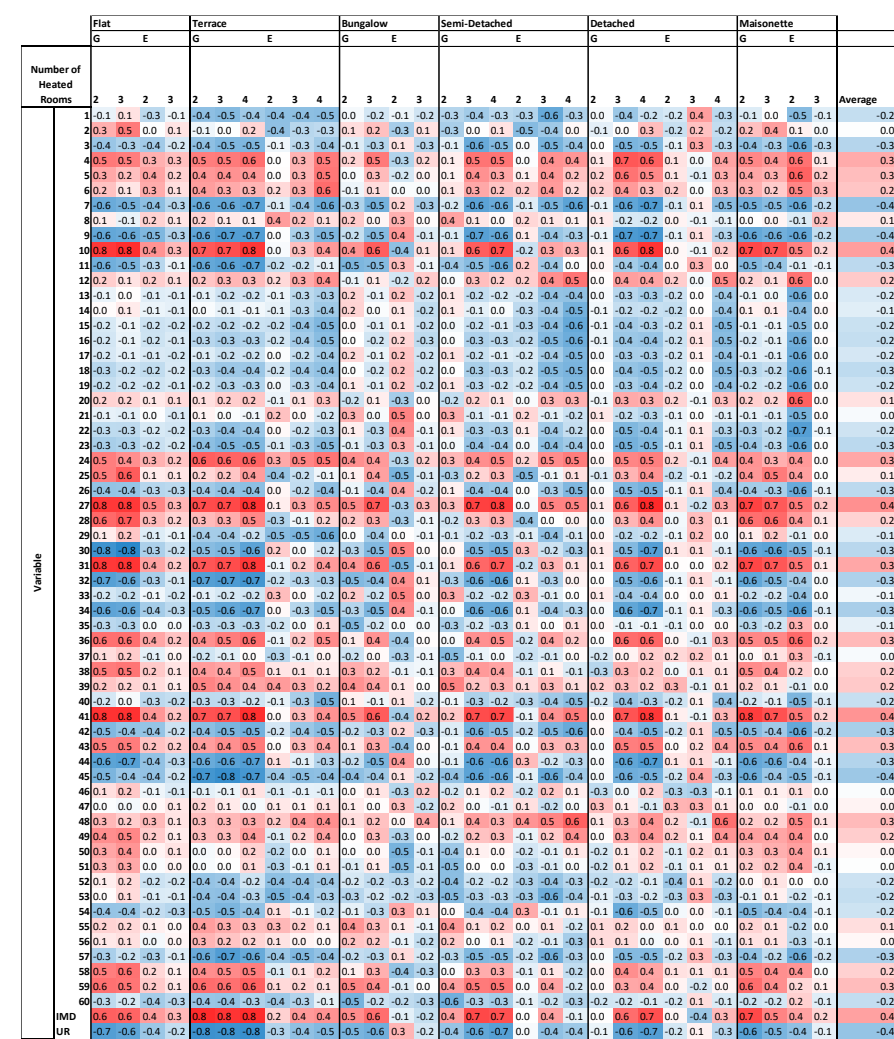

Figure C.2. Spearman Correlation Matrix Test Results for Dwellings with Solid Un-Insulated Walls.

\section{C.3. Key and Socio-economic and Demographic Variable Descriptions}

\section{$\begin{array}{lllllllllll}\text { Key } & -1.0 & -0.8 & -0.6 & -0.4 & 0.0 & 0.2 & 0.4 & 0.6 & 0.8 & 1.0\end{array}$ \\ G: Natural Gas-Fired Boiler and Radiators E: Electric Storage Heaters}

Table C.1

Socio-economic and Demographic Variables [Note for Editor: Single Column Table]

\begin{tabular}{|c|c|}
\hline Name & Variable Description \\
\hline 1 & Persons aged 0 to 4 \\
\hline 2 & Persons aged 5 to 14 \\
\hline 3 & Persons aged 25 to 44 \\
\hline 4 & Persons aged 45 to 64 \\
\hline 5 & Persons aged 65 to 89 \\
\hline 6 & Persons aged 90 and over \\
\hline 7 & Number of persons per hectare \\
\hline 8 & Persons living in a communal establishment \\
\hline 9 & Persons aged over 16 who are single \\
\hline 10 & Persons aged over 16 who are married or in a registered same-sex civil partnership \\
\hline 11 & Persons aged over 16 who are divorced or separated \\
\hline 12 & Persons who are white \\
\hline 13 & Persons who have mixed ethnicity or are from multiple ethnic groups \\
\hline 14 & Persons who are Asian/Asian British: Indian \\
\hline 15 & Persons who are Asian/Asian British: Pakistani \\
\hline 16 & Persons who are Asian/Asian British: Bangladeshi \\
\hline 17 & Persons who are Asian/Asian British: Chinese and Other \\
\hline 18 & Persons who are Black/African/Caribbean/Black British \\
\hline 19 & Persons who are Arab or from other ethnic groups \\
\hline 20 & Persons whose country of birth is the United Kingdom or Ireland \\
\hline 21 & Persons whose country of birth is in the old EU (pre 2004 accession countries) \\
\hline 22 & Persons whose country of birth is in the new EU (post 2004 accession countries) \\
\hline 23 & Main language is not English and cannot speak English well or at all \\
\hline 24 & Households with no children \\
\hline 25 & Households with non-dependent children \\
\hline 26 & Households with full-time students \\
\hline 27 & Households who live in a detached house or bungalow \\
\hline 28 & Households who live in a semi-detached house or bungalow \\
\hline 29 & Households who live in a terrace or end-terrace house \\
\hline 30 & Households who live in a flat \\
\hline 31 & Households who own or have shared ownership of property \\
\hline 32 & Households who are social renting \\
\hline 33 & Households who are private renting \\
\hline 34 & Occupancy room rating -1 or less \\
\hline 35 & Individuals day-to-day activities limited a lot or a little (Standardised Illness Ratio) \\
\hline 36 & Persons providing unpaid care \\
\hline 37 & $\begin{array}{l}\text { Persons aged over } 16 \text { whose highest level of qualification is Level 1, Level } 2 \text { or } \\
\text { Apprenticeship }\end{array}$ \\
\hline 38 & Persons aged over 16 whose highest level of qualification is Level 3 qualifications \\
\hline 39 & $\begin{array}{l}\text { Persons aged over } 16 \text { whose highest level of qualification is Level } 4 \text { qualifications and } \\
\text { above }\end{array}$ \\
\hline 40 & Persons aged over 16 who are schoolchildren or full-time students \\
\hline
\end{tabular}


$41 \quad$ Households with two or more cars or vans

Persons aged between 16 and 74 who use public transport to get to work Persons aged between 16 and 74 who use private transport to get to work Persons aged between 16 and 74 who walk, cycle or use an alternative method to get to work

Persons aged between 16 and 74 who are unemployed

Employed persons aged between 16 and 74 who work part-time

Employed persons aged between 16 and 74 who work full-time

Employed persons aged between 16 and 74 who work in the agriculture, forestry or fishing industries

Employed persons aged between 16 and 74 who work in the mining, quarrying or construction industries

Employed persons aged between 16 and 74 who work in the manufacturing industry

Employed persons aged between 16 and 74 who work in the energy, water or air Employed persons aged bet

conditioning supply industries 16 and 74 who work in the wholesale and retail trade; Employed persons aged between 16 and 74 who work
repair of motor vehicles and motor cycles industries

repair of motor vehicles and motor cycles indsties Employed persons aged between 16 and 74 who work in the transport or storag

industries service activities industries

Employed persons aged between 16 and 74 who work in the information and communication or professional, scientific and technical activities industries

Employed persons aged between 16 and 74 who work in the financial, insurance or real estate industries

Employed persons aged between 16 and 74 who work in the administrative or support service activities industries

Employed persons aged between 16 and 74 who work in the in public administration or defence; compulsory social security industries

Employed persons aged between 16 and 74 who work in the education sector

Employed persons aged between 16 and 74 who work in the human health and social work activities industrie

MD Index of Multiple Deprivation

UR - Unemployment Rate for Year 2016

\section{Appendix D. Distribution of Deprivation for Heating Types}

\section{D.1 Index of Multiple Deprivation}

Note: the index of multiple deprivation (IMD) 2015 is the official measure of relative deprivation for small areas (or neighborhoods) in England. The IMD ranks every small area in England from 1 (most deprived area) to 32,844 (least deprived area) (Department for Communities and Local Government, 2015).

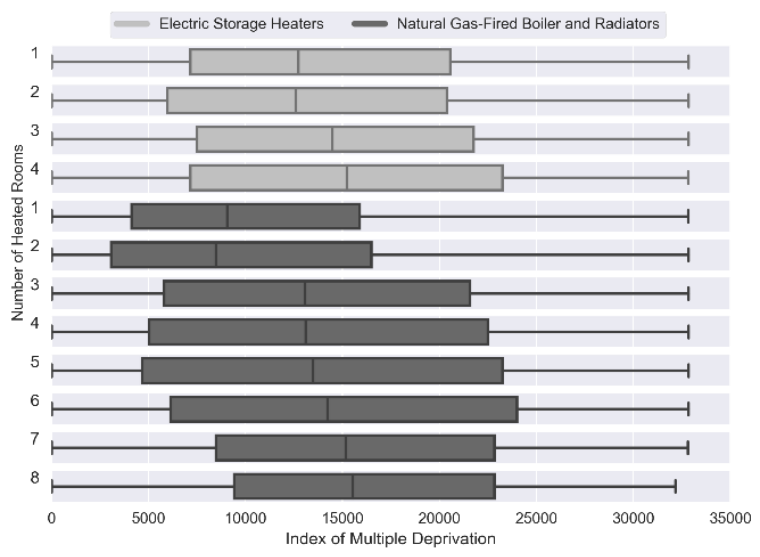

Figure D.1. The distribution of deprivation in flats with cavity insulated walls heated with either electric storage heaters or a natural gas-fired boiler and radiators.

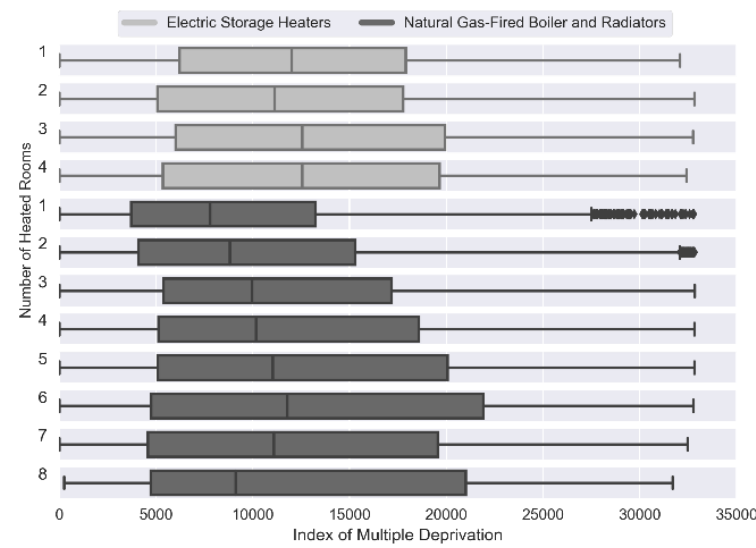

Figure D.2. The distribution of deprivation in flats with solid un-insulated walls heated with either electric storage heaters or a natural gas-fired boiler and radiators.

\section{D.2 Unemployment}

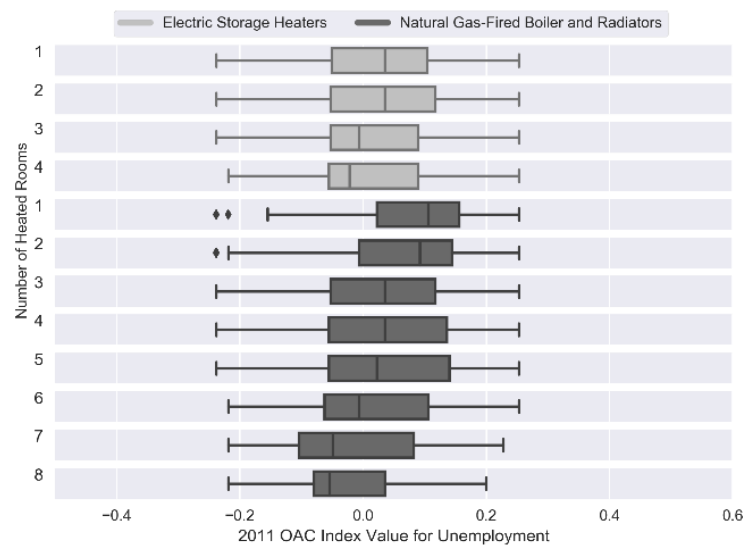

Figure D.3. The distribution of unemployment in flats with cavity insulated walls heated with either electric storage heaters or a natural gas-fired boiler and radiators.

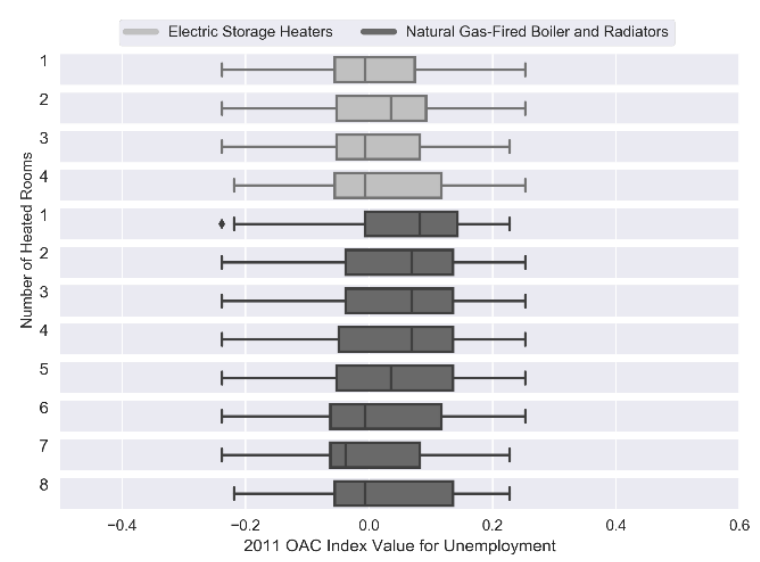

Figure D.4. The distribution of unemployment in flats with solid un-insulated walls heated with either electric storage heaters or a natural gas-fired boiler and radiators.

D.3 Households that are Socially Renting 


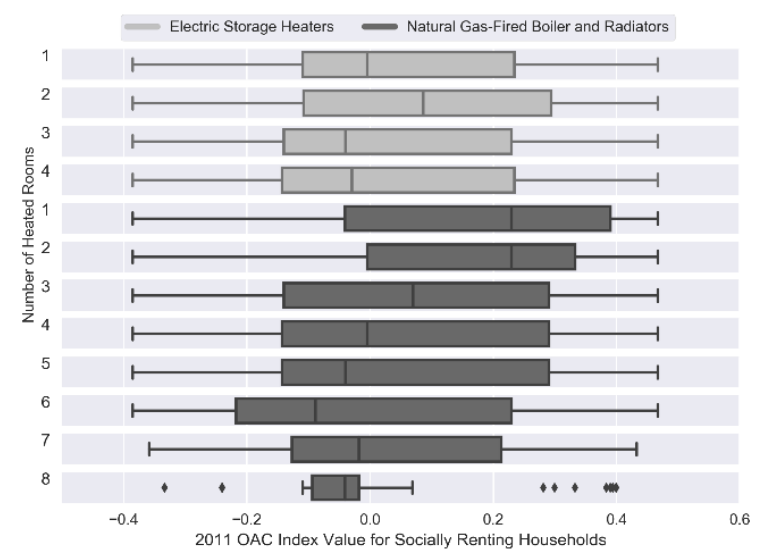

Figure D.5. The distribution of social housing in flats with cavity insulated walls heated with either electric storage heaters or a natural gas-fired boiler and radiators.

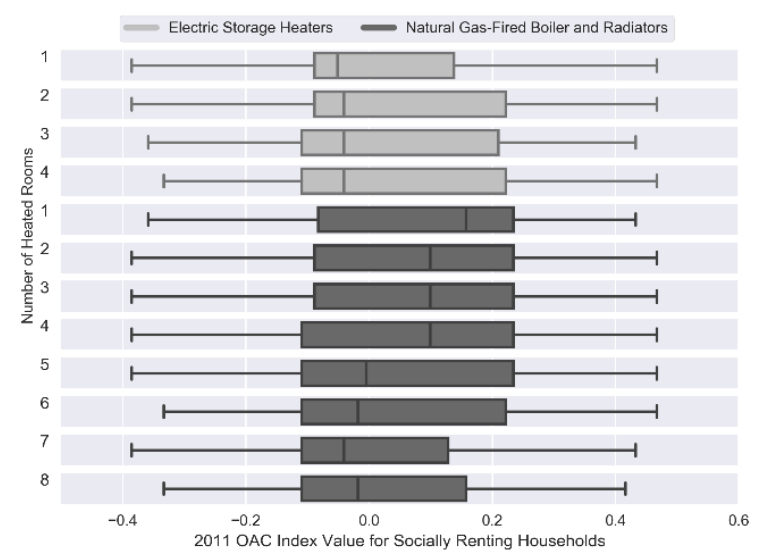

Figure D.6. The distribution of social housing in flats with solid un-insulated walls heated with either electric storage heaters or a natural gas-fired boiler and radiators. The lower the IMD number the more deprived a residential area is.

\section{Appendix E. Baseline Heating Systems Characteristics}

\section{Assumptions}




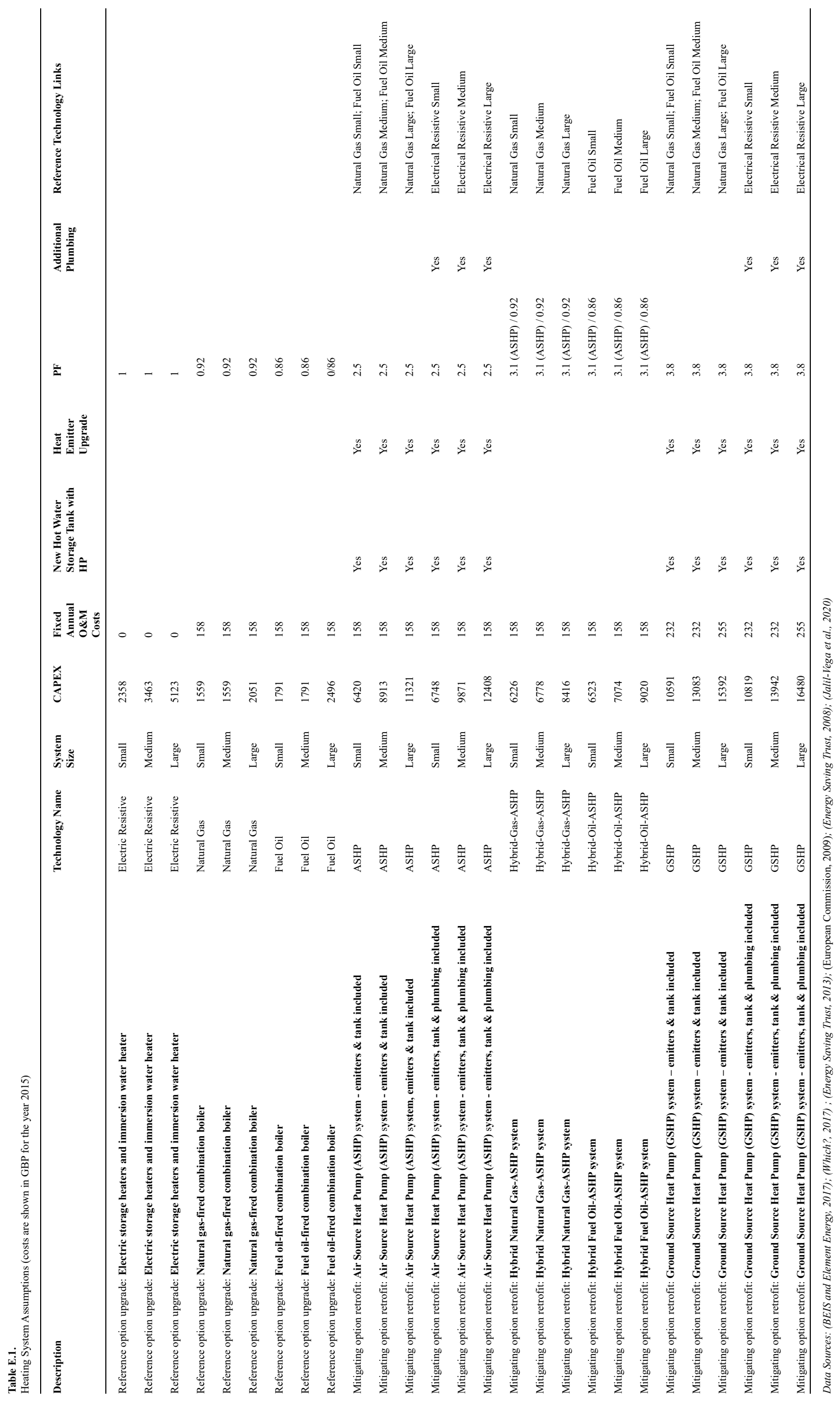




\section{Appendix F. Sensitivity Analysis for key Technology \\ Variables}

F.1 Sensitivity Analysis: Seasonal Performance Factor (SPF) - ASHPs
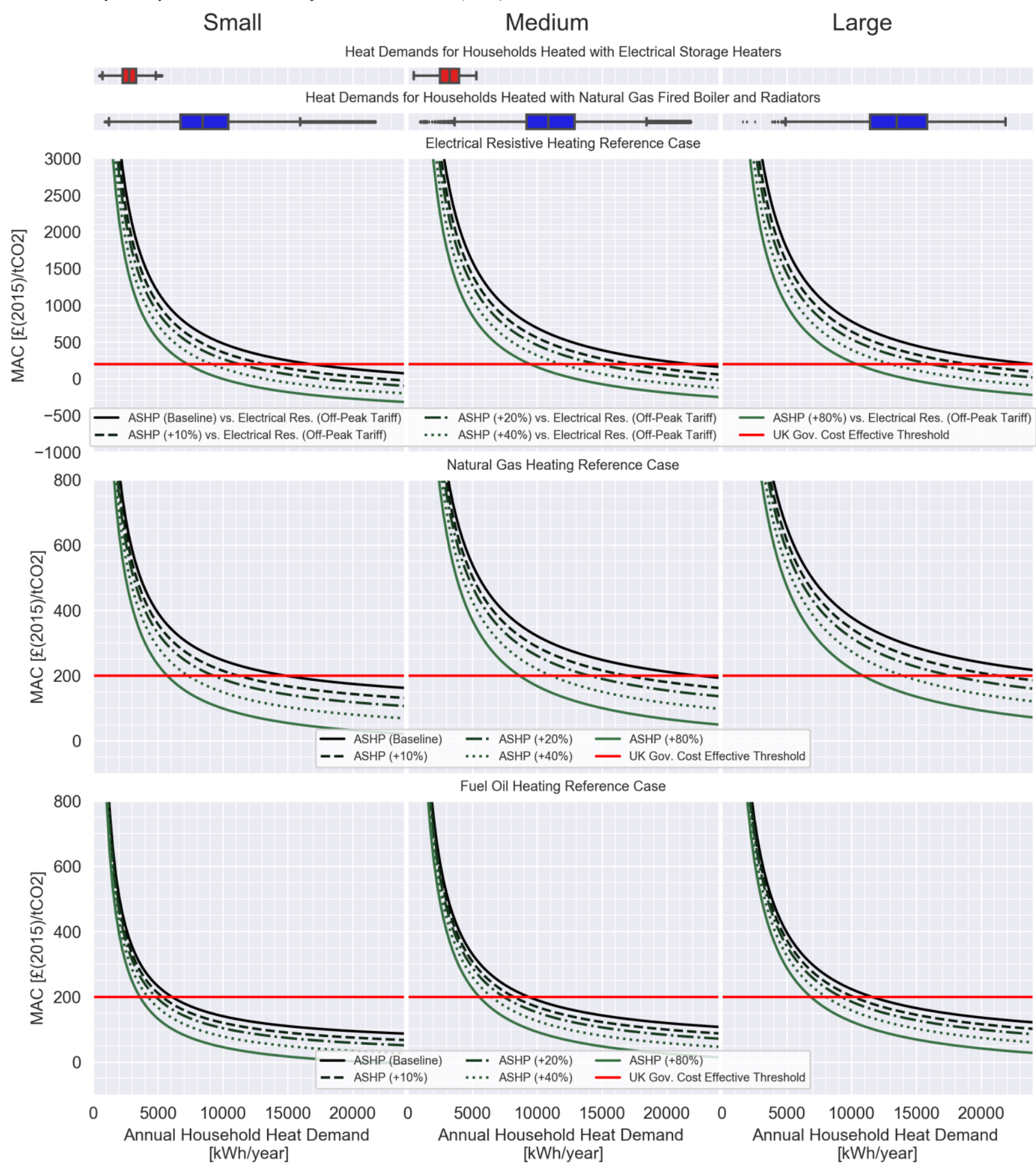

Figure F.1. Displaying MAC results for sensitivity analysis into SPF for standalone ASHP systems. Baseline SPF values are increased by the following percentages $10 \%, 20 \%, 40 \%$ and $80 \%$, as indicated by each respective legend. 

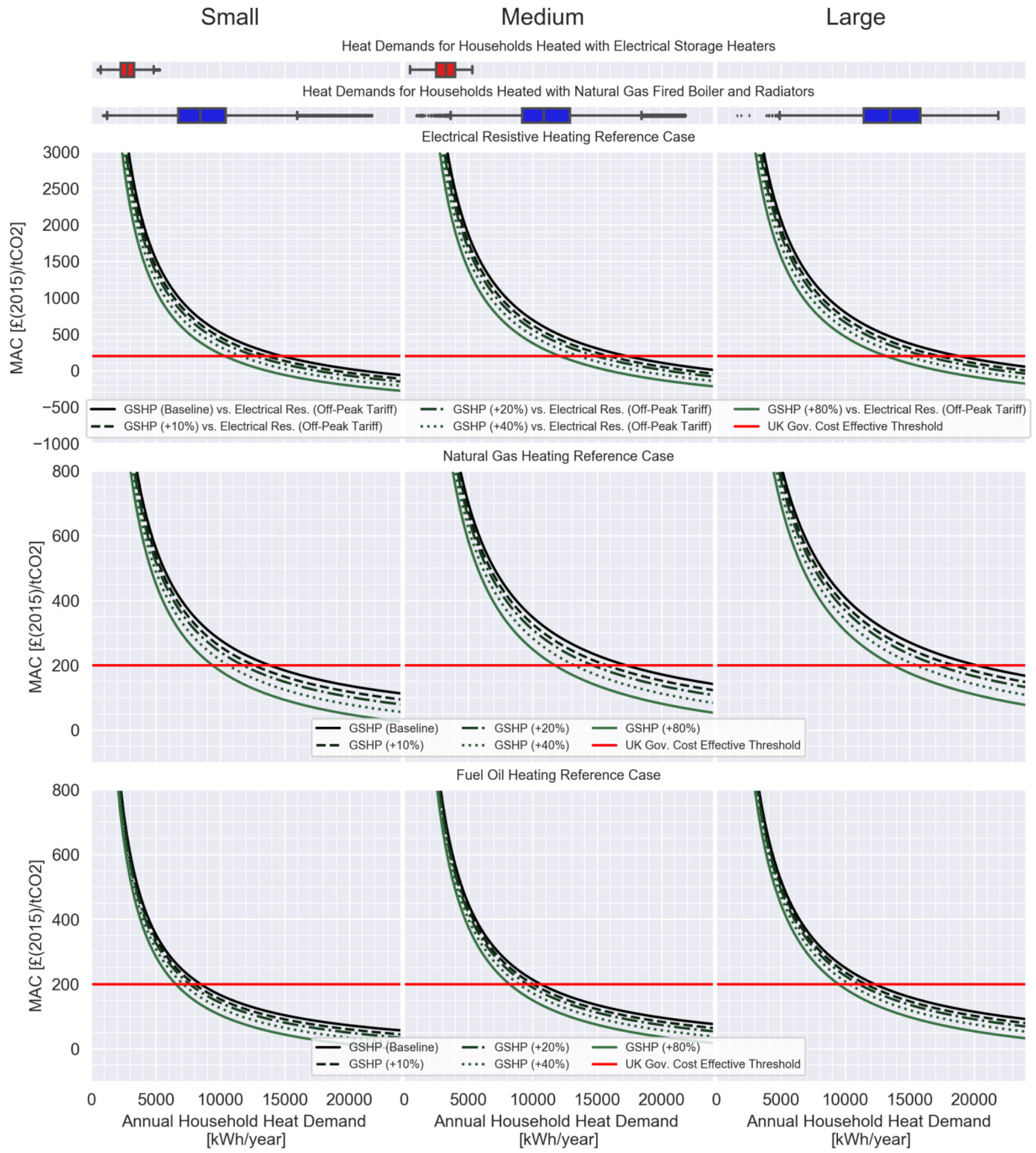

Figure F.2. Displaying MAC results for sensitivity analysis into SPF for standalone GSHP systems. Baseline SPF values are increased by the following percentages $10 \%, 20 \%, 40 \%$ and $80 \%$, as indicated by each respective legend. 
F.3 Sensitivity Analysis: Seasonal Performance Factor (SPF) - Hybrid HPs

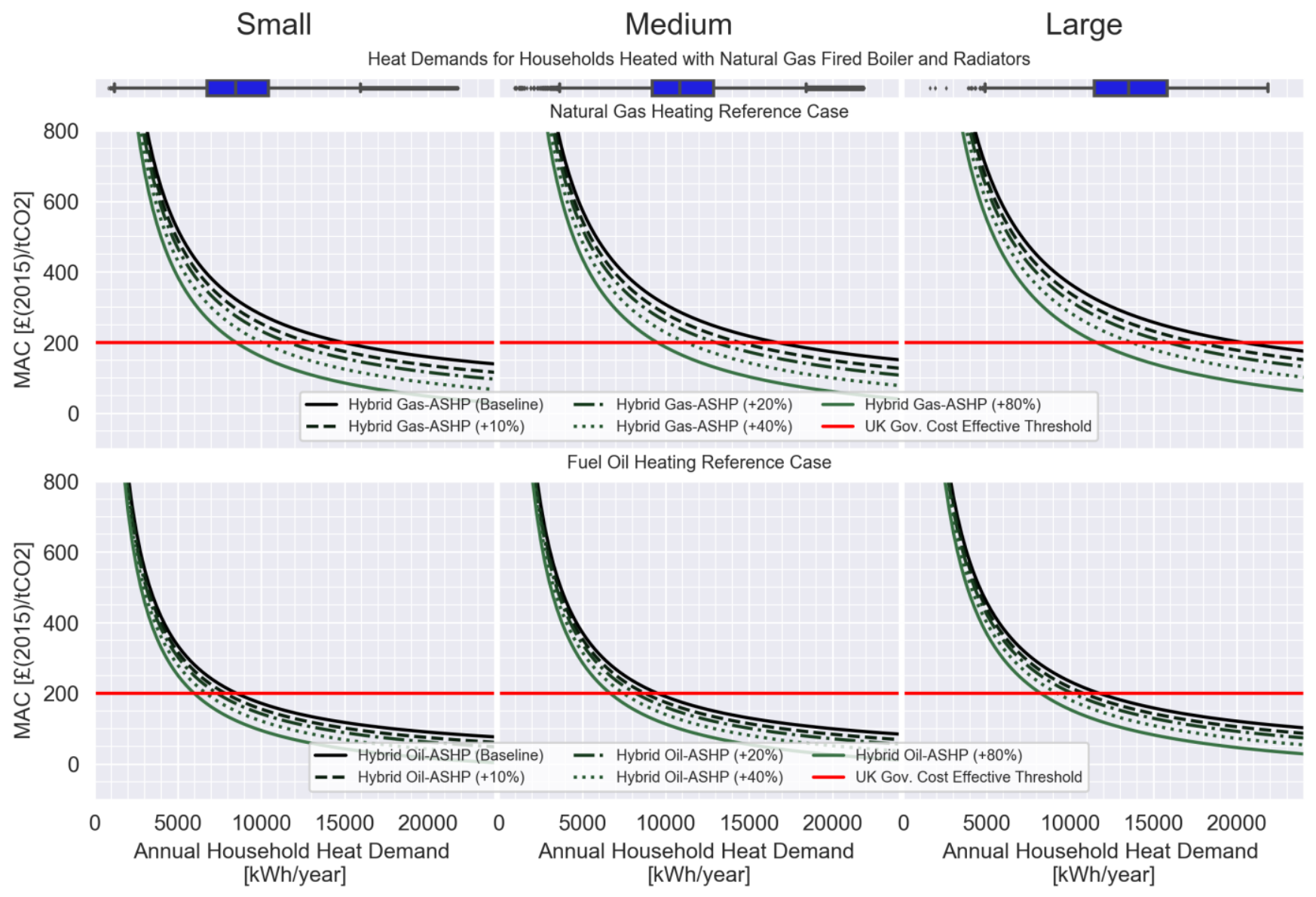

Figure F.3. Displaying MAC results for sensitivity analysis into SPF for hybrid HP systems. Baseline SPF values are increased by the following percentages $10 \%, 20 \%, 40 \%$ and $80 \%$, as indicated by each respective legend.

\section{F.4 Sensitivity Analysis: CAPEX - Hybrid HPs}

\section{Small}

Medium
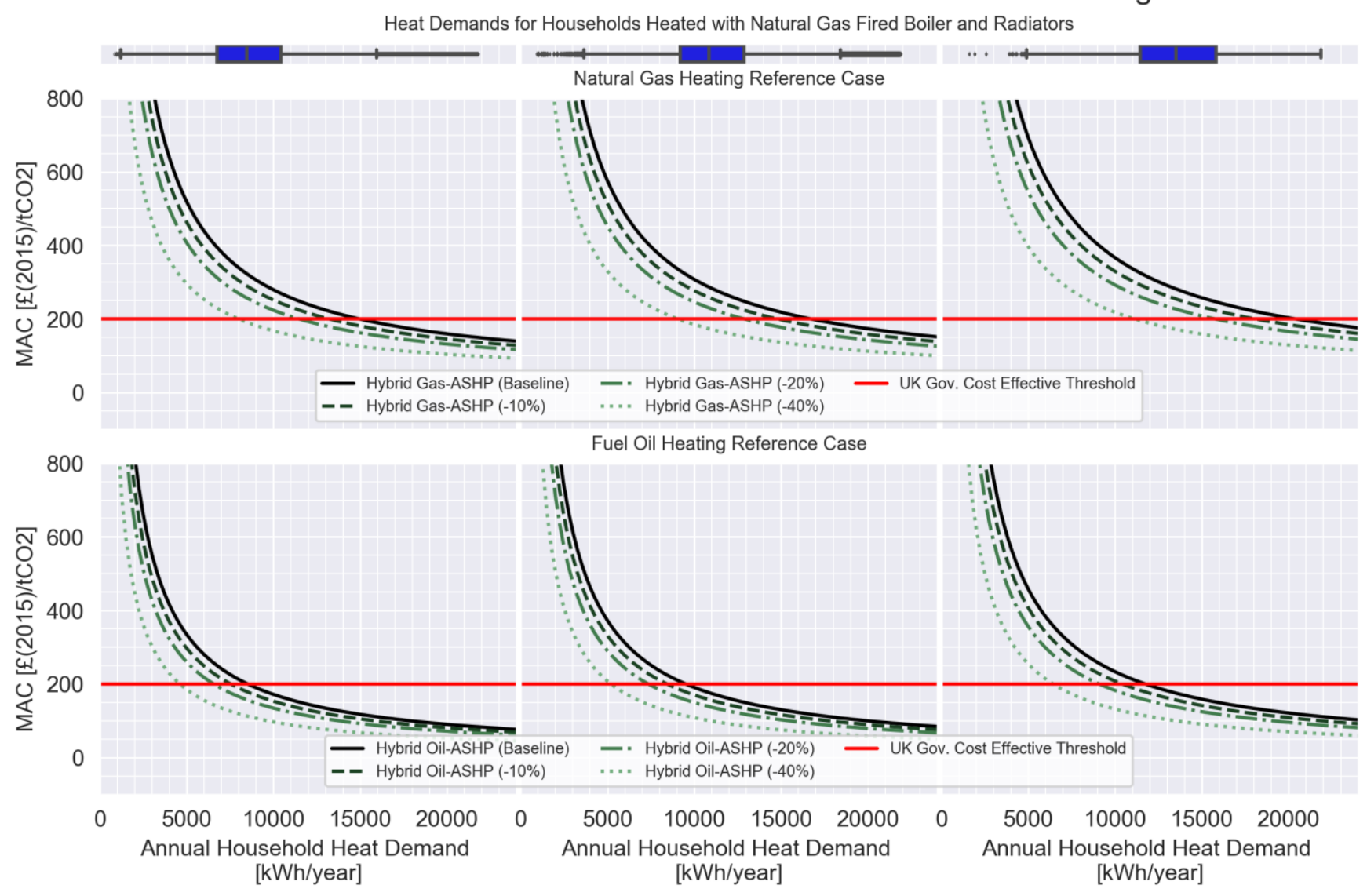

Figure F.4. Displaying MAC results for sensitivity analysis into CAPEX for hybrid HP systems. Baseline CAPEX values, for HP associated CAPEX, are decreased by the following percentages $10 \%, 20 \%$ and $40 \%$, as indicated by each respective legend. 

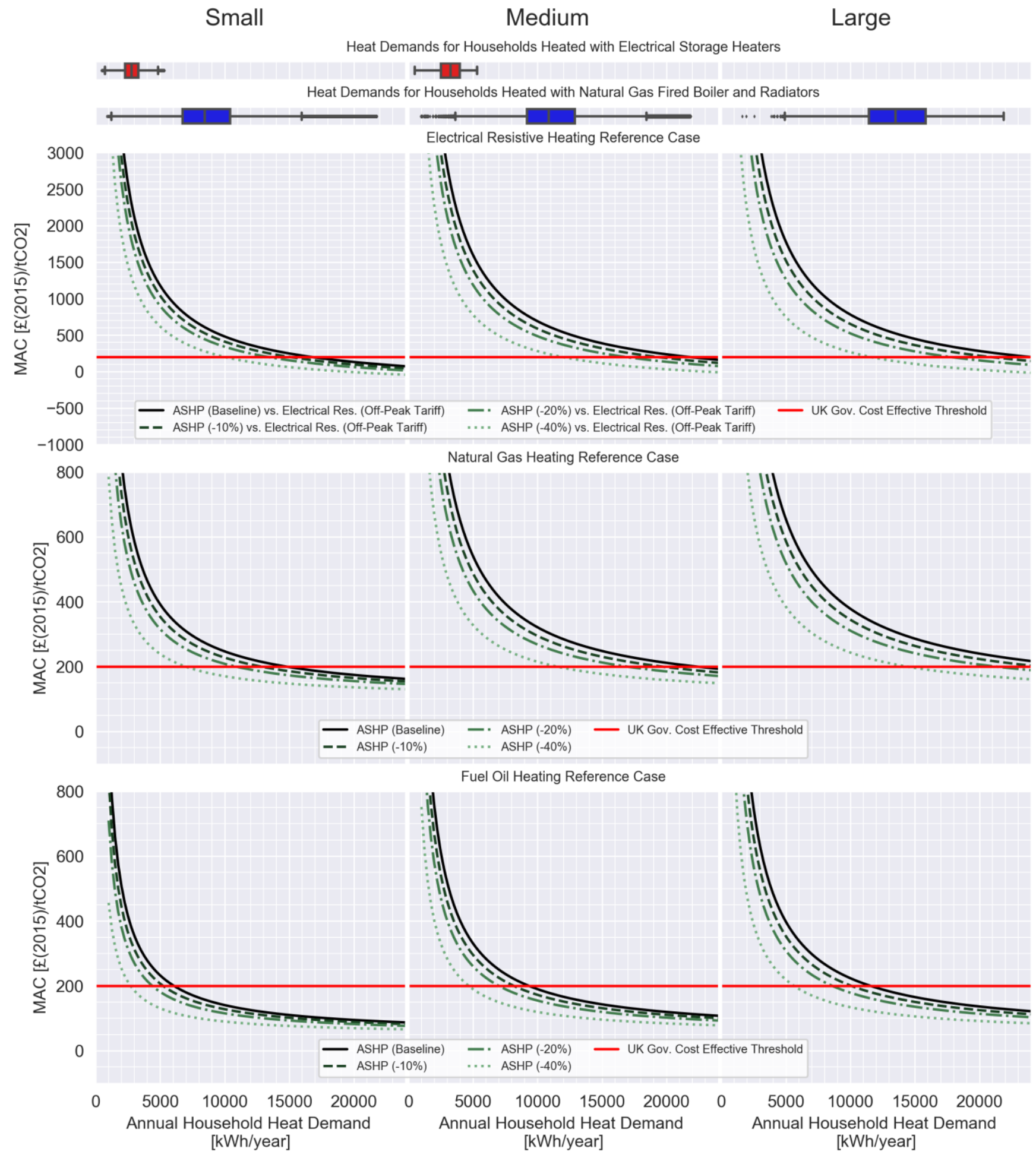

Figure F.5. Displaying MAC results for sensitivity analysis into CAPEX for standalone ASHP systems. Baseline CAPEX values are decreased by the following percentages $10 \%, 20 \%$ and $40 \%$, as indicated by each respective legend. 

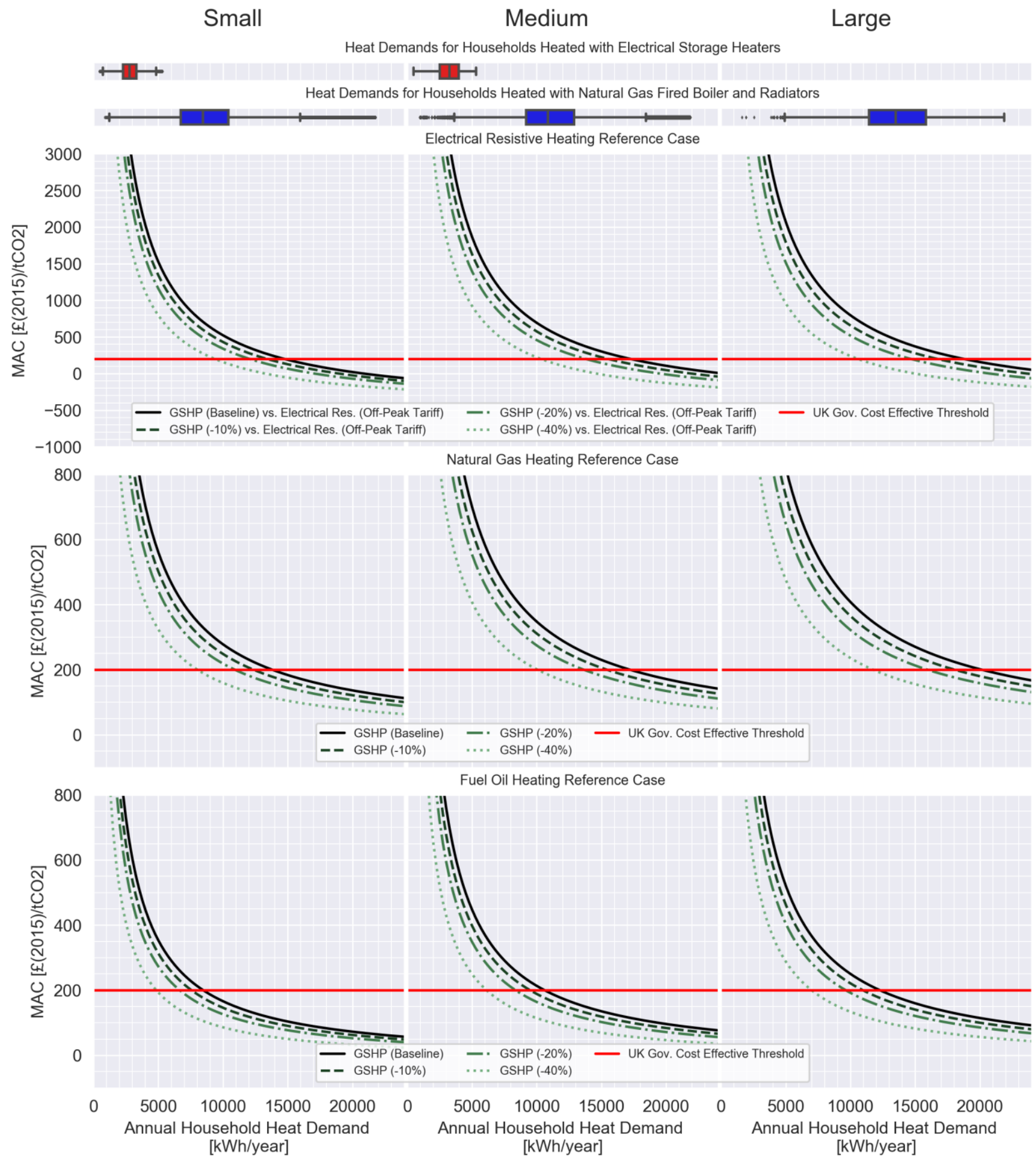

Figure F.6. Displaying MAC results for sensitivity analysis into CAPEX for standalone GSHP systems. Baseline CAPEX values are decreased by the following percentages $10 \%, 20 \%$ and $40 \%$, as indicated by each respective legend. 


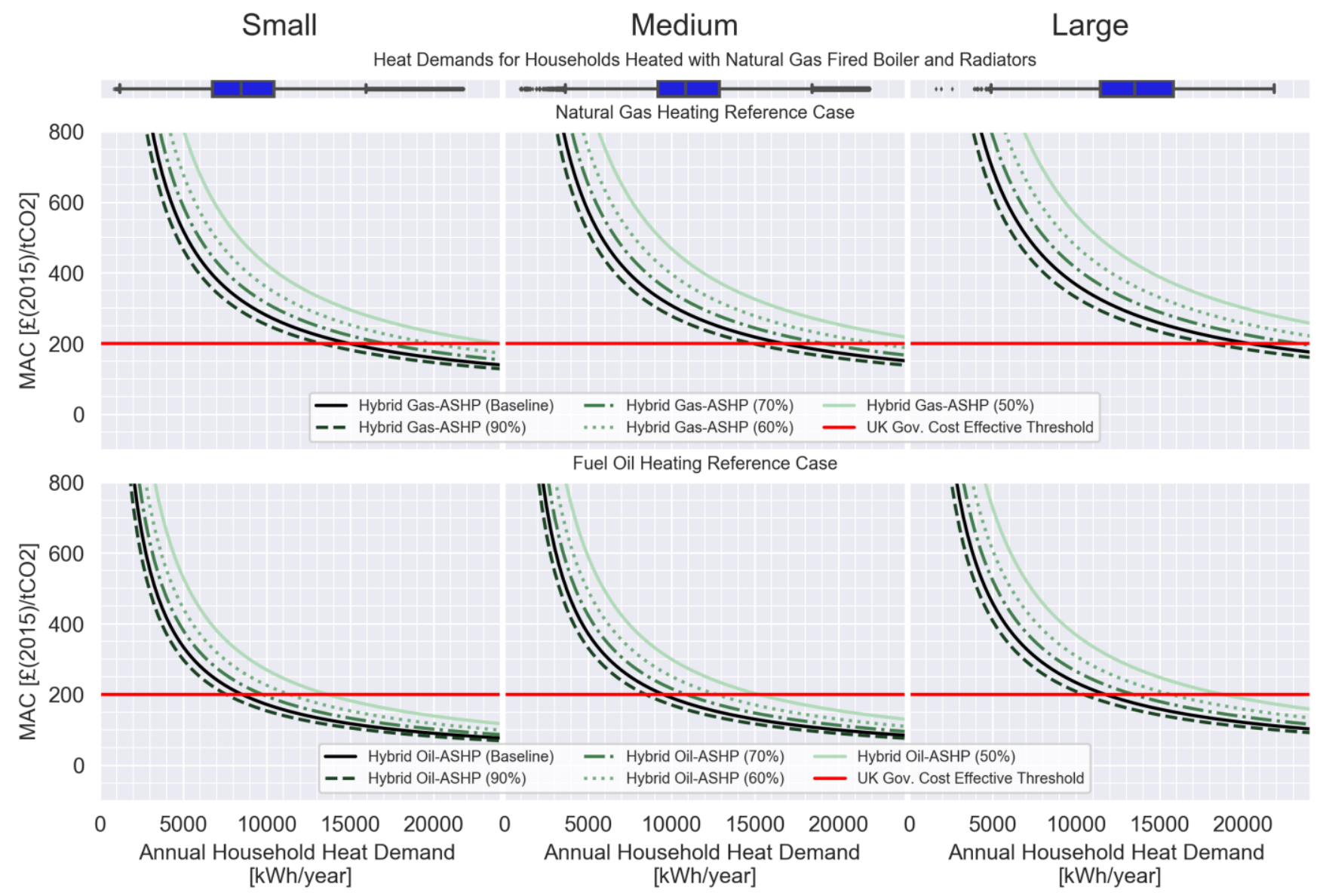

Figure F.7. Displaying MAC results for sensitivity analysis into the percentage of space heat demand serviced by the ASHP in a hybrid system. The baseline percentage of $80 \%$ space heat demand is altered by $10 \%$ increments, as indicated by each respective legend.

\section{References}

BEIS, 2020a. Renewable Heat Incentive statistics [WWW Document]. https://www.gov.uk/government/collections/renewableheat-incentive-statistics (accessed 3.23.20).

BEIS, 2020b. Digest of UK Energy Statistics (DUKES): natural gas.

BEIS, 2019a. Sub-national electricity consumption data 2016 and 2017.

BEIS, 2019b. Sub-national gas consumption data 2016 and 2017.

BEIS, 2019c. Green Book supplementary guidance: valuation of energy use and greenhouse gas emissions for appraisal.

BEIS, 2019d. Average unit costs and fixed costs for electricity for UK regions (QEP 2.2.4) [WWW Document]. URL https://www.gov.uk/government/statistical-datasets/annual-domestic-energy-price-statistics (accessed 5.5.19).

BEIS, 2018a. Energy consumption in the UK.

BEIS, 2018b. Sub-national consumption statistics: methodology and guidance booklet.

BEIS, 2018c. Government announces $£ 6$ billion package to help end fuel poverty [WWW Document]. URL https:/www.gov.uk/government/news/governmentdelivers-on-manifesto-pledge-with-6-billion-package-tohelp-end-fuel-poverty-and-drive-innovation-in-energyefficiency (accessed 3.5.18).

BEIS, 2017a. The Clean Growth Strategy: Leading the way to
a
low
carbon
future. https://doi.org/10.1002/cplu.201300278

BEIS, 2017b. The Clean Growth Strategy: Leading the way to a low carbon future.

BEIS, 2017c. Fuel poverty trends 2017.

BEIS, Element Energy, 2017. Hybrid Heat Pumps.

Belaïd, F., Bakaloglou, S., Roubaud, D., 2018. Direct rebound effect of residential gas demand: Empirical evidence from France. Energy Policy 115, 23-31. https://doi.org/10.1016/j.enpol.2017.12.040

BRE Group, 2012. The Government's Standard Assessment Procedure for Energy Rating of Dwellings.

Broad, O., Hawker, G., Dodds, P.E., 2020. Decarbonising the UK residential sector: The dependence of national abatement on flexible and local views of the future. Energy

Policy. https://doi.org/10.1016/j.enpol.2020.111321

CBI Climate Change Task Force, 2007. Climate change: Everyone's business - options for greenhouse gas reduction in the UK. https://doi.org/10.1007/BF01094082

CCC, 2019a. Reducing UK emissions - 2019 Progress Report to Parliament.

CCC, 2019b. Net Zero - The UK's contribution to stopping global warming.

CCC, 2019c. UK housing: Fit for the future?

CCC, 2018. Hydrogen in a low-carbon economy.

Clinch, J.P., Healy, J.D., 2003. Valuing improvements in comfort from domestic energy-efficiency retrofits using a 
trade-off simulation model. Energy Economics. https://doi.org/10.1016/S0140-9883(03)00051-3

DECC, 2014. Estimates of heat use in the United Kingdom in 2013. https://doi.org/10.1007/s11340-016-0232-4

DECC, 2013. United Kingdom Housing Energy Fact File. https://doi.org/URN: 13D/276

DECC, 2012. Dynamic Dispatch Model (DDM).

Department for Communities and Local Government, 2015. The English Index of Multiple Deprivation [WWW Document]. https://www.gov.uk/government/statistics/englishindices-of-deprivation-2015 (accessed 9.1.19).

Dodds, P.E., 2014. Integrating housing stock and energy system models as a strategy to improve heat decarbonisation assessments. Applied Energy 132, 358-369. https://doi.org/10.1016/j.apenergy.2014.06.079

Druckman, A., Jackson, T., 2008. Household energy consumption in the UK: A highly geographically and socio-economically disaggregated model. Energy Policy 36 , 3167-3182. https://doi.org/10.1016/j.enpol.2008.03.021

Druckman, A., Sinclair, P., Jackson, T., 2008. A geographically and socio-economically disaggregated local household consumption model for the UK. Journal of Cleaner Production 16, 870-880. https://doi.org/10.1016/j.jclepro.2007.05.004

Energy Saving Trust, 2018. Air source heat pumps [WWW Document].

URL

http://www.energysavingtrust.org.uk/renewableenergy/heat/air-source-heat-pumps (accessed 8.20.18).

Energy Saving Trust, 2013. The heat is on: heat pump field trials phase 2 .

Energy Saving Trust, 2008. Domestic heating by oil: boiler systems - guidance for installers and specifiers.

European Commission, 2009. DIRECTIVE 2009/28/EC OF THE EUROPEAN PARLIAMENT AND OF THE COUNCIL. Official Journal of the European Union L 140/16, 16-62.

Font Vivanco, D., Kemp, R., van der Voet, E., 2016. How to deal with the rebound effect? A policy-oriented approach. Energy https://doi.org/10.1016/j.enpol.2016.03.054

Frederiks, E.R., Stenner, K., Hobman, E. V., 2015. Household energy use: Applying behavioural economics to understand consumer decision-making and behaviour. Renewable and Sustainable Energy Reviews 41, 13851394. https://doi.org/10.1016/J.RSER.2014.09.026

Gale, C.G., Singleton, A.D., Bates, A.G., Longley, P.A., 2016. Creating the 2011 area classification for output areas (2011 OAC). Journal of Spatial Information Science 12, 1-27. https://doi.org/10.5311/JOSIS.2016.12.232

Gillingham, K., Palmery, K., 2014. Bridging the energy efficiency gap: Policy insights from economic theory and empirical evidence. Review of Environmental Economics and Policy 8, 18-38. https://doi.org/10.1093/reep/ret021

Green Match, 2018. Combi Boilers [WWW Document]. URL https://www.greenmatch.co.uk/boilers/combi-boilers (accessed 6.1.18).

Hall, L.M.H., Buckley, A.R., 2016. A review of energy systems models in the UK: Prevalent usage and categorisation. Applied Energy 169, 607-628. https://doi.org/http://dx.doi.org/10.1016/j.apenergy.2016 .02 .044

Hawker, G.S., Bell, K.R.W., 2019. Making energy system models useful: Good practice in the modelling of multiple vectors. Wiley Interdisciplinary Reviews: Energy and Environment 1-15. https://doi.org/10.1002/wene.363

HM Government, 2019. Climate Change Act 2008 (2050 Target Amendment) Order 2019.

HM Government, 2018. The Renewable Heat Incentive Scheme Regulations 2018. UK.

HM Government, 2008. Climate Change Act 2008. https://doi.org/10.1136/bmj.39469.569815.47

HM Government, 2000. Warm Homes and Energy Conservation Act 2000.

HM Revenue \& Customs, 2014. Energy-saving materials and heating equipment (VAT Notice 708/6) [WWW Document]. URL https://www.gov.uk/guidance/vat-onenergy-saving-materials-and-heating-equipment-notice7086 (accessed 6.10.19).

HM Treasury, 2018. The Green Book: appraisal and evaluation in central government.

Huang, S.K., Kuo, L., Chou, K.L., 2016. The applicability of marginal abatement cost approach: A comprehensive review. Journal of Cleaner Production 127, 59-71. https://doi.org/10.1016/j.jclepro.2016.04.013

Ibrahim, N., Kennedy, C., 2016. A Methodology for Constructing Marginal Abatement Cost Curves for Climate Action in Cities. Energies 9. https://doi.org/10.3390/en9040227

IET, 2019. Transitioning to hydrogen.

IRENA, 2018. Renewable Power Generation Costs in 2017.

Jalil-Vega, F., García Kerdan, I., Hawkes, A.D., 2020. Spatiallyresolved urban energy systems model to study decarbonisation pathways for energy services in cities. Applied https://doi.org/10.1016/j.apenergy.2019.114445

Kannan, R., Strachan, N., S, Pye, S., G, Anandarajah, G., BaltaOzkan, N., 2007. UK MARKAL Model Documentation.

Kelly, J.A., Fu, M., Clinch, J.P., 2016. Residential home heating: The potential for air source heat pump technologies as an alternative to solid and liquid fuels. Energy https://doi.org/10.1016/j.enpol.2016.09.016

Kelly, N.J., Tuohy, P.G., Hawkes, A.D., 2014. Performance assessment of tariff-based air source heat pump load shifting in a UK detached dwelling featuring phase change-enhanced buffering. Applied Thermal Engineering. https://doi.org/10.1016/j.applthermaleng.2013.12.019

Kesicki, F., Strachan, N., 2011. Marginal abatement cost (MAC) curves: Confronting theory and practice. Environmental Science and Policy 14, 1195-1204. https://doi.org/10.1016/j.envsci.2011.08.004

Loulou, R., Labriet, M., 2008. ETSAP-TIAM: the TIMES integrated assessment model Part I: Model structure. Computational Management Science 5, 7-40. https://doi.org/10.1007/s10287-007-0046-z

McKinsey \& Company, 2009. Pathways to a low-carbon economy: Version 2 of the global greenhouse gas abatement cost curve. New York. https://doi.org/10.1016/j.enpol.2010.01.047

MCS, 2020. About Us [WWW Document]. URL https://mcscertified.com/about-us/ (accessed 4.6.20).

Meier, A., Rosenfeld, A.H., Wright, J., 1982. Supply curves of conserved energy for California's residential sector. Energy 7, 347-358. https://doi.org/10.1016/03605442(82)90094-9

Met Office, 2019. UK temperature, rainfall and sunshine timeseries [WWW Document]. URL https://www.metoffice.gov.uk/climate/uk/summaries/act 
ualmonthly (accessed 5.9.19).

Ministry of Housing Communities \& Local Government, 2018. Energy Performance of Buildings Data: England and Wales [WWW Document]. URL https://epc.opendatacommunities.org/ (accessed 3.27.18).

Mitsubishi Electric, 2016. Service \& Maintenance Plans for Homeowners [WWW Document]. URL https://les.mitsubishielectric.co.uk/assets/Uploads/cbce9 e3316/MELSMART-SERV-MAINTHOMEOWNER.pdf (accessed 3.21.20).

National Grid, 2017. GTYS 2017 - Charts and data.

NIBE, 2020. HEAT PUMP SYSTEM SERVICING [WWW Document]. URL HEAT PUMP SYSTEM SERVICING (accessed 3.21.20).

Office for National Statistics, 2018. Jobseeker's Allowance with rates and proportions [WWW Document]. URL https://www.nomisweb.co.uk/query/select/getdatasetbyt heme.asp? opt $=3 \&$ theme $=\&$ subgrp $=($ accessed 12.3.18).

Ofgem, 2020. How to switch energy supplier and shop for a better deal [WWW Document]. URL https://www.ofgem.gov.uk/consumers/household-gasand-electricity-guide/how-switch-energy-supplier-andshop-better-deal (accessed 4.3.20).

Ofgem, 2017. Decision on revised Typical domestic Consumption Values for gas and electricity and economy 7 consumption split.

Ofgem, 2015. Insights paper on households with electric and other non-gas heating.

Oluleye, G., Allison, J., Hawker, G., Kelly, N., Hawkes, A.D., 2018. A two-step optimization model for quantifying the flexibility potential of power-to-heat systems in dwellings. Applied Energy 228, 215-228. https://doi.org/10.1016/J.APENERGY.2018.06.072

Sachs, J., Meng, Y., Giarola, S., Hawkes, A., 2019. An agentbased model for energy investment decisions in the residential sector. Energy 172, 752-768. https://doi.org/10.1016/j.energy.2019.01.161

Sathaye, J., Shukla, P.R., 2013. Methods and Models for Costing Carbon Mitigation. Annual Review of Environment and Resources 38, 137-168. https://doi.org/10.1146/annurev-environ-083111-092115

Schmidt, O., Hawkes, A., Gambhir, A., Staffell, I., 2017. The future cost of electrical energy storage based on experience rates. Nature Energy 2, 17110.

Scottish Government, 2019. Local Heat and Energy Efficiency Strategies (LHEES): phase 1 pilots - technical evaluation.

Seebauer, S., 2018. The psychology of rebound effects: Explaining energy efficiency rebound behaviours with electric vehicles and building insulation in Austria. Energy Research and Social Science. https://doi.org/10.1016/j.erss.2018.08.006

Su, Y.W., 2019. Residential electricity demand in Taiwan: Consumption behavior and rebound effect. Energy Policy 124, 36-45. https://doi.org/10.1016/j.enpol.2018.09.009

UK Government, 2019. The Value Added Tax (Reduced Rate) (Energy-Saving Materials) Order 2019. UK.

UK Parliament, 2019. Energy efficiency: building towards net zero: Government Response to the Committee's TwentyFirst Report of Session 2017-19.

Vellei, M., Natarajan, S., Biri, B., Padget, J., Walker, I., 2016. The effect of real-time context-aware feedback on occupants' heating behaviour and thermal adaptation. Energy and Buildings. https://doi.org/10.1016/j.enbuild.2016.03.045

Which?, 2017. Home Heating Systems [WWW Document].
URL https://www.which.co.uk/reviews/home-heatingsystems/article/home-heating-systems/the-best-heatingfor-your-home (accessed 6.1.18). 